Review

\title{
Lipid metabolism in the rumen: New insights on lipolysis and biohydrogenation with an emphasis on the role of endogenous plant factors
}

\author{
Arianna Buccioni ${ }^{\mathrm{a}}$, Mauro Decandia ${ }^{\mathrm{b}}$, Sara Minieri ${ }^{\mathrm{a}}$, Giovanni Molle $^{\mathrm{b}}$, Andrea Cabiddu $^{\mathrm{b}, *}$ \\ a Dipartimento di Scienze Zootecniche, Università di Firenze, Via delle Cascine, 5, 50144 Firenze, Italy \\ b Dipartimento per la Ricerca nelle Produzioni Animali, Agris, Località Bonassai, 07040 Olmedo Sassari, Italy
}

\section{A R T I C L E I N F O}

\section{Article history:}

Received 10 March 2011

Received in revised form 15 February 2012

Accepted 15 February 2012

\section{Key words:}

Biohydrogenation

Lipolysis

PUFA

Fresh forage

Endogenous factor

In vitro study

\begin{abstract}
A B S T R A C T
Diet composition is the major factor influencing the fatty acid composition of meat and milk from ruminants because the fatty acids (FA) which reach the duodenum are, at least in part, of dietary origin as well as the result of rumen microbial biohydrogenation (BH) of dietary lipids. In this review, effects of synthesis of conjugated linoleic (CLA) and linolenic (CLNA) acid isomers in the rumen, effects of the lipids in herbage, and plant endogenous factors on synthesis of nutraceutical fatty acids are discussed. Discovery of beneficial FA in ruminant products, such as CLA and other $\omega-3$ FA, stimulated many studies in the last 20 years, including those on the roles of minor FA intermediates on rumen BH and mammary gland metabolism. Much of this research was targeted at identifying the intermediates formed during $\mathrm{BH}$ as well as the rumen microbial ecology involved in these processes. However, shifting the research to feedstuff endogenous factors which influence lipolysis (LP) and losses of polyunsaturated FA in the rumen may be of interest in identifying nutritional strategies to manipulate FA profiles in ruminant products. The presence of FA with healthful properties in milk or meat from ruminants can be enhanced by inclusion of fresh forages in their diet. Hence, there is increasing interest in the crucial role of endogenous LP, plant secondary metabolites (PSM) and polyphenol oxidase (PPO) on ruminal BH. To better understand the pathways through which PSM or PPO impact FA metabolism, characterization of lipids in fresh forages suggests the important role of the diet matrix on the ruminal fate of lipids. A critical discussion of the role of odd chain branched FA (OBCFA) is also reported, including potential impacts on rumen microbial metabolism. Finally, new insights into lipid metabolism from in vitro techniques are discussed.
\end{abstract}

(c) 2012 Elsevier B.V. All rights reserved.

\footnotetext{
Abbreviations: BH, biohydrogenation; CLA, conjugated LA; CLNA, conjugated LNA; DAPA, diaminopimelic acid; DHA, docosahexaenoic acid; DHS, dihydrosphingosine; DPG, diphosphatidylglycerol; DM, dry matter; EPA, eicosapentanoic acid; ER, endoplasmic reticulum; FA, fatty acid; FAME, fatty acid methyl esters; F/C, forage/concentrate ratio; FFA, free FA; FO, fish oil; GA, galactolipids; GL, glycolipids; GPL, glycerophospholipids; GPSL, glycophosphosphingolipids; GSC, glucosylceramide; LA, linoleic acid; LAB, bacteria associated with liquid phase; LA-I, linoleic isomerase; LNA, linolenic acid; LP, lipolysis; MFD, milk fat depression; MGDG, monogalactosyldiacylglicerol; ML, membrane lipids; MUFA, mono unsaturated FA; NFA, neutral FA; OA, oleic acid; OBCFA, odd branched chain FA; OCFA, odd chain FA; PA, palmitic acid; PB, purine bases; PBP, protein bound phenols; PC, phosphatidylcholine; PE, phosphatidylethanolamine; PG, phosphatidylglycerol; PHS, phytosphingosine; PI, phosphatidylinositol; PL, phospholipids; PSM, plant secondary metabolites; PUFA, polyunsaturated FA; PPO, polyphenol oxidase; PS, phosphatidylserine; RA, rumenic acid; RNA, rumelenic acid; SA, stearic acid; SAB1, bacteria loosely attached to feed particles; SAB2, bacteria firmly attached to feed particles; SFA, saturated FA; SHL, sphingolipids; SL, plant sulpholipids; SPH, glycosphingolipids; SQDG, 1,2 diacylglicerol-3-(6-sulpho- $\alpha$-D-quinovopyranosyl)-sn glycerol; TAG, triacylglycerides; TFA, trans FA; UFA, unsaturated FA; VA, vaccenic acid; VFA, volatile fatty acids; VNA, vaccelenic acid.
}

* Corresponding author. Tel.: +39079 2842 349; fax: +39 079389450 .

E-mail address: acabiddu@agrisricerca.it (A. Cabiddu). 


\section{Contents}

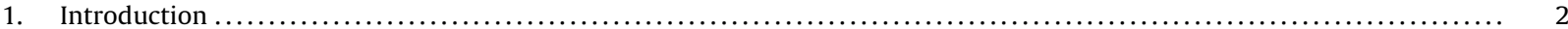

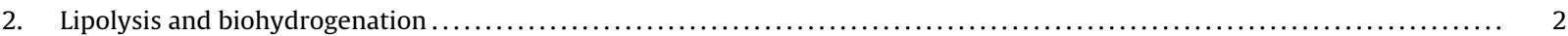

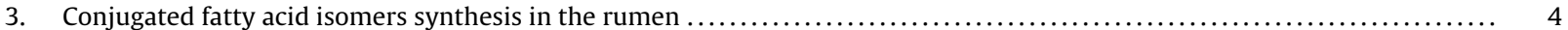

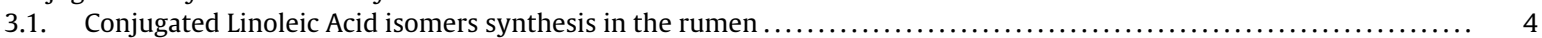

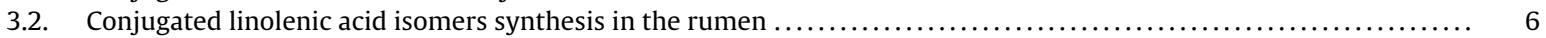

4. Lipid fractions in herbage, their manipulation and effects on PUFA ruminal biohydrogenation.....................

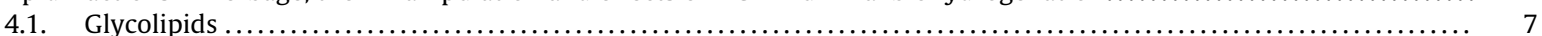

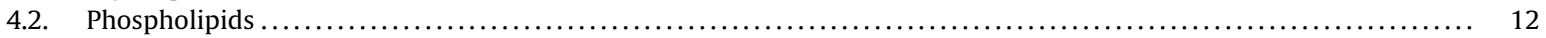

5. Plant endogenous factors which influence fatty acid profile, PUFA ruminal lipolysis and biohydrogenation ................ 13

6. Odd and branched chain fatty acids: a new frontier in the study of rumen microbial metabolism .................... 16

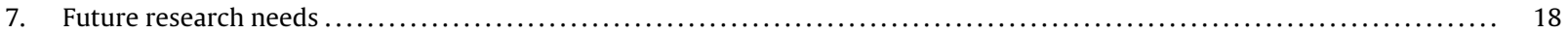

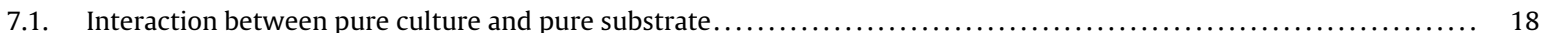

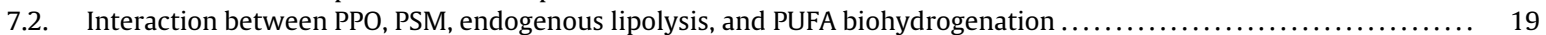

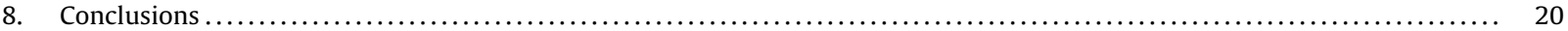

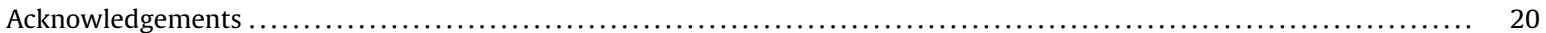

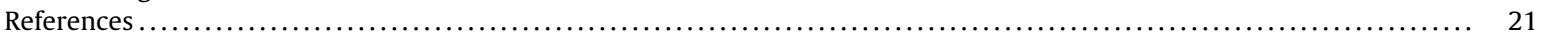

\section{Introduction}

The rumen environment is characterized by $10^{10}$ bacteria, $10^{7}$ protozoa, $10^{6}$ fungi and yeasts per ml of live liquor, a temperature of $38-39^{\circ} \mathrm{C}$, a normal range of $\mathrm{pH}$ between 6.0 and 6.7, and a redox potential of $-150-350 \mathrm{mV}$. Any deviation from these conditions may influence the microbial population and its fermentation products. While feed is within the rumen a small amount of dietary fatty acids (FA) is absorbed and catabolised to volatile FA (VFA) or to $\mathrm{CO}_{2}$. However, microorganisms are able to synthesize remarkable amounts of FA de novo from precursor carbohydrates and to hydrogenate unsaturated FA (UFA). Thus FA which reach the duodenum are of dietary origin as well as the result of microbial activity. In recent decades many authors (e.g., Harfoot, 1978; Palmquist and Jenkins, 1980; Jenkins, 1993) have studied the fate of dietary lipids during rumen fermentation, emphasizing the two major processes in which esterified lipids are involved (i.e., lipolysis (LP) and biohydrogenation (BH)). This microbial activity leads to synthesis of long chain FA as the pool for conjugated linoleic acid (CLA), conjugated linolenic (CLNA) isomers and other BH intermediates. While some of these are found in low concentrations in the rumen liquor, they accumulate in tissue lipids and milk fat (Destaillats et al., 2005; Akraim et al., 2007). Interesting information has been obtained from adoption of in vitro fermentation techniques in these investigations.

The aim of this review is to present an overview of long chain UFA metabolism pathways in the rumen, factors influencing synthesis of nutraceutical FA, and research needs in the field of ruminal lipid metabolism. Ruminal metabolism of FA from fresh forage is also reviewed, with an update on recent research into plant endogenous mechanisms involved in LP, and their influence on loss of PUFA in the rumen.

\section{Lipolysis and biohydrogenation}

Lipolysis results in release of free FA (FFA) from esters to allow $\mathrm{BH}$, which is reduction of the number of double bonds on the carbon chain of the FA. Since subsequent hydrogenation can only happen if the carboxyl moiety is free, LP is a necessary step in BH. Thus if only small quantities of dietary PUFA reach the duodenum, this may be due to a missing LP, and may be what determines the rate of hydrogenation in the rumen. This group of reactions appears to be a process utilised by microorganisms to protect themselves from toxic effects of UFA (Dehority, 2003).

After ingestion, dietary esterified lipids are hydrolysed to FFA and glycerol as well as to small amounts of mono- and diglycerides by microbial lipases, which are extra-cellular enzymes assembled in small beads (Jenkins, 1993). The number of microorganisms capable of hydrolysing esters is low, and their activity is highly specific (Henderson, 1971; Fay et al., 1990). Various bacterial strains of Butyrivibrio fibrisolvens and Anaerovibrio lipolytica are capable of hydrolysing the ester bond, but $B$. fibrisolvens lipase hydrolyses phospholipids, A. lipolytica hydrolyses only tri- and di-glycerides, and their rates of hydrolysis differ. Lipase activity also occurs in ciliatae protozoa, but not in fungi (Dehority, 2003), although their contribution is less than that of bacteria.

FFA may also arise from hydrolysis of plant galactolipids and phospholipids catalysed by several bacterial galactosidases and phospholipases (e.g., phospholipase A and phospholipase C), produced by rumen microbes (Jenkins, 1993).

The half life of free UFA is relatively short due to their rapid hydrogenation by rumen microbes into the corresponding saturated configuration. BH has been estimated at 600 and $900 \mathrm{~g} / \mathrm{kg}$ of PUFA, and only contributes to a small extent to the recycling of metabolic hydrogen because only 1-2\% of it is used for this purpose (Czerkawski, 1984). Harvatine and Allen (2006) completed an in vivo experiment with lactating dairy cows to determine rates of FA biohydrogenation of fat supplements with different grades of unsaturation, and developed a kinetic model of ruminal BH. Based on their results, they showed that passage rates of C16:0, C18:0 and total C18-carbon FA linearly decreased as UFA increased, while the trans C18:1 fractional 


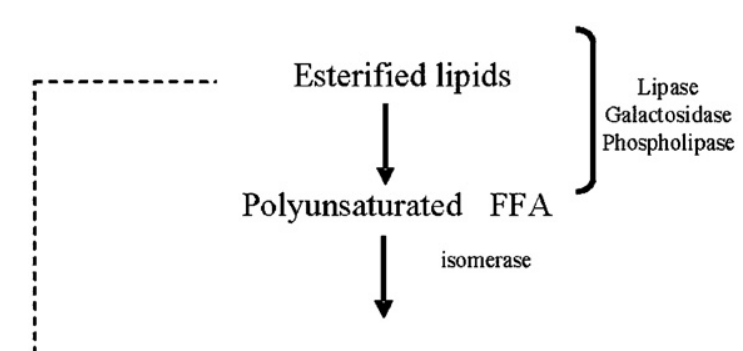

Polyunsaturated Conjugated FFA

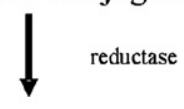

Monounsaturated FFA

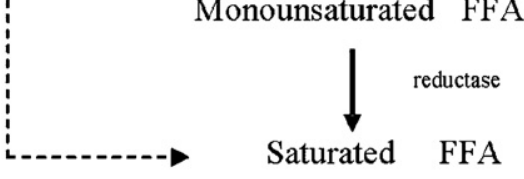

Fig. 1. Lipolysis and biohydrogenation scheme.

From Jenkins (1993), modified.

passage rate was affected quadratically with a maximum rate for the intermediate treatment. Increasing UFA increased the extent of C18:2 and C18:3 biohydrogenation, and decreased the extent of C18:1 and trans C18:1 biohydrogenation.

Bacteria are thought to be mainly responsible for $\mathrm{BH}$, while the contribution of protozoa is regarded as negligible (Singh and Hawke, 1979). This activity is mainly associated with bacteria attached to feed particles, rather than with those in free liquid. Free UFA are adsorbed onto feed particle surfaces and hydrogenated (Harfoot et al., 1975; Gerson et al., 1988). However, Nam and Garnsworthy (2007) studied the BH rate of linoleic acid (C18:2 cis-9 cis-12, LA) by mixed rumen fungi in an in vitro experiment and noted that rumen fungi can biohydrogenate LA, but that their BH is lower than that of rumen bacteria. The end product of fungal biohydrogenation is vaccenic acid (C18:1 trans-11, VA), as it is for rumen bacteria, and Orpinomyces is the most active biohydrogenating fungus.

The feedstuffs which comprise ruminant diets often contain LA, C18:3 cis-9 cis-12 cis-15 (linolenic acid, LNA) and C18:1 cis-9 (Oleic acid, OA). Most bacteria involved in BH are cellulolytic with the most important being B. fibrisolvens, identified by Kepler et al. (1966) as able to BH the LA. At present more than 32 strains of this bacterium have been identified and characterized. Clostridium proteoclasticum, reclassified as Butyrivibrio proteoclasticus (Moon et al., 2008), is the only bacteria isolated from the rumen capable of converting PUFA to SFA. This microorganism converts C18:1 substrates to C18:0 while Propionibacterium acnes hydrates cis-9 C18:1 and trans-11 C18:1 to 10-OH-C18:0, which is further oxidized to 10-O-C18:0 (Kim et al., 2008; McKain et al., 2010). Fig. 1 shows the BH scheme of FA esters.

When the fibre content of the diet is lowered, and higher levels of concentrates are used in the diet, there is a reduction in the number of cellulolytic bacteria in the rumen (Latham et al., 1972; Doreau and Ferlay, 1994; Kalscheur et al., 1997; Loor et al., 2004). Thus this kind of diet favours lipids which pass the rumen without being reduced, especially OA and LA(Chilliard et al., 2007). However when the diet is high in concentrates, other alternative BH pathways occur with the appearance of some trans fatty acids (TFA), characterized by a trans double bond in the carbon chain (Griinari and Bauman, 2006).

Other dietary factors which diminish LP and rumen BH are advanced maturity of forage and/or forage which has been ground into extremely fine particles (Gerson et al., 1986, 1988). In the latter case the adherence of bacteria to feed particle surfaces is poor and the transit rate through the rumen is increased, thereby reducing time of exposure to microbial activity.

The amount and type of fat added to the diet can influence the BH of lipids in the rumen. For example, the FA profile of marine oil is rich in C20:5 n-3 (eicosapentaenoic acid, EPA) and C22:6n-3 (docosahexaenoic acid, DHA) while oil seeds such as soybean, sunflower, canola and linseed mainly contain C18 PUFA and MUFA. These FA are hydrogenated in the rumen and induce synthesis of BH intermediates such as conjugated and trans isomers (Chilliard et al., 2007).

Rumen bacterial populations which LP and BH can be divided into three main groups being: bacteria associated with the liquid phase (LAB) and bacteria either loosely (SAB1) or firmly (SAB2) attached to feed particles (Czerkawski, 1986; Legay-Carmier and Bauchart, 1989). Bessa et al. (2009) studied the FA composition of LAB, SAB1 and SAB2 with the aim of identifying these bacteria from their FA profile, and found marked differences in FA composition between LAB and SAB (i.e., detachable plus undetachable solid associated bacteria) populations, consistent with others (Bauchart et al., 1990a; Kim et al., 2005; Vlaeminck et al., 2006b). LAB had a lower FA content and a higher proportion (g/kg FA) of odd branched chain FA (OBCFA) than did SAB, which had a higher proportion of C18 biohydrogenation derived FA (C18:0; especially trans C18:1 and CLA). The ratio between branched-chain and odd-linear-chain FA was also higher in LAB (2.26) than in SAB (1.46). Bessa et al. (2009) observed differences in the proportions of FA between SAB1 and SAB2. Compared to SAB1, the SAB2 compartment had lower proportions of odd-chain FA and of some branched-chain FA (iso-C14:0 and iso-C16:0 and anteiso-C17:0), but the 


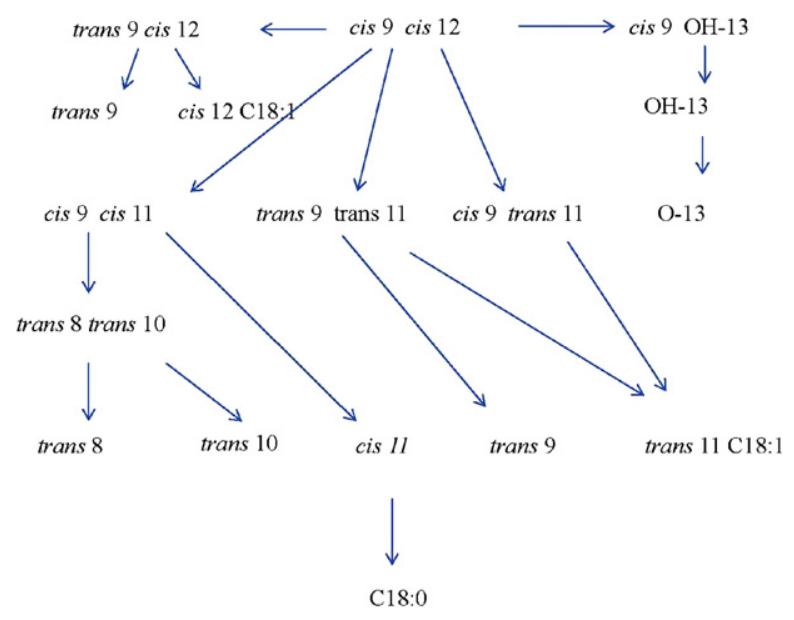

From Shingfield et al. (2010), modified.

Fig. 2. Biohydrogenation of linoleic acid.

ratio between branched-chain and odd linear-chain FA was the same. SAB2 also had higher proportions of trans C18:1, CLA and particularly of 18:2 n-6 and 18:3n-3 than SAB1.

\section{Conjugated fatty acid isomers synthesis in the rumen}

\subsection{Conjugated Linoleic Acid isomers synthesis in the rumen}

Microorganisms may use BH as a means of defence against UFA toxicity, and LA isomerization is one of the steps which makes FA inoffensive in this regard. CLA is a pool of geometrical and positional isomers of LA (cis-9, cis-12 C18:2) which contain a conjugated bond system located from positions 2 to 17 of the molecular structure. Each positional isomer has four geometric isomers being: cis, trans; trans, cis; cis, cis; trans, trans, for a total of 56 possible isomers. The double bond positions of CLA isomers actually identified in the rumen and in milk fat range from 6,8- to 13,15-C18:2 in most possible geometrical configurations, for a total of 32 isomers (Bessa et al., 2000; Kramer et al., 2004; Shingfield et al., 2008).

Rumenic acid (RA; cis-9, trans-11 C18:2 isomer) is synthesized in small amounts in the rumen by LA isomerization, mostly in the mammary gland by $\Delta^{9}$ desaturation of VA in lactating ruminants (Griinari and Bauman, 1999; Kramer et al., 1999; Griinari et al., 2000; Mosley et al., 2006; Shingfield and Griinari, 2007; Bernard et al., 2009). Palmquist et al. (2004) provided data to suggest that this also occurs in the adipose tissue of lambs.

The first step of the LA BH pathway consists of enzymatic isomerization by cis-12, trans-11 isomerase, which turns the cis-12 bond into a trans-11 (RA, Fig. 2). This isomerase has a specific requirement for free carboxylic groups, and particularly ones with the isolated diene characterized by a geometry "cis-9, cis-12". Linoleic isomerase (LA-I) does not need a cofactor, or any activating functional groups, as it is bonded to the bacterial cell wall and has been partially purified and characterized in a limited number of bacteria in studies of Kepler and Tove (1967) and Kepler et al. (1970) and Yokoyama and Davis (1971). After the bond in the trans-11 position has been formed, hydrogenation to the cis-9 position is effected by a microbial reductase of $B$. fibrisolvens (Hughes et al., 1982). These initial steps take place rapidly, while the BH of VA to stearic acid (SA) is much slower, and results in VA accumulation in the rumen. Thus when different groups of microorganisms are involved, VA hydrogenation seems to be the step which determines the rate of $\mathrm{BH}$.

Kemp and Lander (1984), classified bacteria involved in BH into two groups being: group A bacteria which can isomerize and hydrogenate LA to VA (i.e., B. fibrisolvens), and group B bacteria which can saturate VA to SA (i.e., Fusocillus spp., C. proteoclasticum). In 2003, Van de Vossenberg and Joblin (2003) isolated a strain of Butyrivibrio hungatei from bovine rumen which was able to form SA from LA, a rare example of bacterium which, acting alone, can directly reduce PUFA to the corresponding saturated FA.

In the 1980s, the literature suggested that the contribution of protozoa to BH was due to activity of ingested bacteria (Singh and Hawke, 1979). However Devillard et al. (2004) observed that the CLA and VA content of rumen protozoal cells was 4-5 fold higher than that in bacteria, which suggests that protozoa may also be a major pool of CLA and VA in the rumen. Yàňez-Ruiz et al. (2006, 2007), using an approach based on real time PCR quantified the contribution of protozoa to duodenal FA flow confirming that these microorganism contribute almost $400 \mathrm{~g} / \mathrm{kg}$ of RA, $300-360 \mathrm{~g} / \mathrm{kg}$ of trans-10, cis-12 CLA and $400 \mathrm{~g} / \mathrm{kg}$ of the VA leaving the rumen by passage. The simplest explanation is that protozoa do not form CLA and VA, but that they are very efficient in incorporating intermediates of bacterial BH (Devillard et al., 2006). However it is difficult to calculate the real contribution of protozoa to FA supply because studies reported by Dehority (2003) showed that protozoa tend to be retained in the rumen, as outflow does not always reflect ruminal concentrations. In contrast, Yàňez-Ruiz et al. 
(2006) showed that the FA within protozoa contribute a significant proportion of the CLA and VA reaching the duodenum of ruminants and that the protozoal FA profile depends on the chemical composition of the animals' diet.

Rumen isomerization also involves other UFA, such us OA, which has been proposed as a rumen precursor of trans C18:1 isomers. Selner and Schultz (1980) observed an increase of C18:1 trans acids in milk fat from cows fed diets rich in OA, and Mosley et al. (2002) showed that this could be attributed to rumen isomerization of OA. However several studies have shown that $\mathrm{OA}$ is the ruminal precursor of hydroxystearic acid (10-OH-C18:0) and of ketostearic acid (10-O-C18:0), whose accumulation in ruminal contents of cattle is directly related to the quantity of OA in the rumen (Jenkins et al., 2006). In addition, McKain et al. (2010) demonstrated that P. acnes DSM 1897 is the main microorganism responsible for OA hydration to $10-\mathrm{OH}-\mathrm{C} 18: 0$, which is further oxidized to $10-\mathrm{O}-\mathrm{C} 18: 0$.

Hudson et al. (1995) isolated two bacterial strains which convert OA to 10-OH-C18:0 in sheep rumen liquor. One, the 10-hydroxystearic-acid-producing bacterial group, consisted of two strains of an anaerobic gram-negative microorganism whose morphology allowed it to be identified as Selenomonas ruminantium. The other, identified as Enterococcus faecalis, consisted of two strains of a facultative anaerobic gram positive chain-forming cocci. The authors showed that there were several differences in representative colonies from rumen fluid of sheep and cows. For example, while in both sheep and cows the strains of Streptococcus bovis, Lactobacillus and Staphylococcus were the most numerous hydration-positive isolates, sheep rumen fluid also contained hydration-positive strains of Enterococcus and Pediococcus which can hydrate UFA. Overall, these findings suggest that lactic acid bacteria are the major UFA hydrating bacteria in the rumen (Hudson et al., 2000).

The amount of VA hydrogenated to C18:0 is affected by conditions in the rumen, the type and the concentration of dietary PUFA, and by dietary polyphenolic substances such as tannins which irreversibly inhibit the process (Harfoot et al., 1973). Vasta et al. (2009a,b) suggested that tannins can reduce ruminal BH because they inhibit activity of rumen microorganisms. Indeed they found that the presence of these polyphenolic substances in rumen liquor (above $0.6 \mathrm{mg} / \mathrm{ml} \mathrm{rumen} \mathrm{fluid)} \mathrm{results}$ in a $23 \%$ increase of VA, a $16 \%$ decrease of SA, but no change in the proportion of CLA, which comes from LA by means of an isomerization catalysed by LA-I, and its activity is only reduced by the presence of tannins. The authors suggested that several changes in BH production occur because tannins act selectively on bacterial strains. Moore et al. (1969) suggested that large amounts of free LA stop the second stage of BH, although this does not occur when LA is in the esterified form. Chilliard et al. $(2001,2003)$ reviewed the effects of nutritional factors affecting milk fat composition of ruminants and suggested, on the basis of literature data, that supplementing diets with marine oil decreases ruminal BH. Chow et al. (2004) showed that fish oil (FO) has no influence on the degree of LP or apparent BH of LA and LNA. The simultaneous decrease in the amount of SA, and the increase in VA and trans-11, cis-15, C18:2 in substrates, when FO is fed indicates that this supplement inhibits the final step of LA and LNA BH. Similar results were reported by Shingfield et al. $(2003,2010)$ and Shingfield and Griinari (2007) in vivo, who also concluded that FO enhances the RA content in milk fat due to the increase in VA.

Wasowska et al. (2006) showed that FO added to ruminant diets is able to modify the rate of BH by decreasing the initial isomerization rate of LA and LNA, and simultaneously increasing VA accumulation. These data agree with Shingfield et al. (2003), who used the omasal sampling technique to measure rumen outflow of FFA. The authors also highlighted the inhibiting effect of feed supplements containing EPA or DHA on growth of B. fibrisolvens, and on its isomerase activity. Similar results were not found with FO, which does not show any effects on the activity of $B$. fibrisolvens in spite of its high proportion of EPA and DHA. Thus FO inhibits ruminal BH through a mechanism which is not completely based on effects on B. fibrisolvens. Huws et al. (2010) noted that including FO in the diet changes the number of several rumen bacterial strains, such as A. lipolytica, F. succinogenes and R. flavefaciens. They also showed that the DNA concentration from B. proteoclasticus strains, which are the only bacterial strains which have been isolated from the rumen capable of biohydrogenating PUFA to C18:0, has a weak relationship with C18:0 flow to the duodenum, suggesting that other bacteria may play a role in BH when FO is fed to cows. These data were confirmed in other studies which examined the specific role of $B$. proteoclasticus strains (Kim et al., 2008; Huws et al., 2011).

Martin and Jenkins (2002) demonstrated that some environmental factors, such as ruminal pH, appear to have a great influence on production of trans C18:1 and CLA isomers. These authors suggested that ruminal pH has to be maintained above 6.0 if synthesis of CLA is to be maximised because cellulolytic bacteria are sensitive to acidic condition.

In the 1990s, Griinari and Bauman postulated that there was a shift in the normal BH pathway (Fig. 3) when ruminants were fed high concentrate/low fibre diets (Griinari et al., 1997, 1998; Griinari and Bauman, 1999). This theory was corroborated by several studies which examined low fibre diets supplemented with plant oils and FO (Piperova et al., 2002; Loor et al., 2004; Shingfield et al., 2005). The presence of fat in a diet with rapidly fermentable carbohydrates and/or a high proportion of starch alters ruminal conditions to induce changes in the rumen bacterial population. As a result, it is very likely that alternative pathways to metabolize FA are activated. It has been demonstrated that LA may be isomerized to RA or trans-10, cis-12 CLA (Griinari and Bauman, 2006), but that isomerization of LA to trans-10, cis-12 CLA converts the cis-9 bond to a trans-10 through activity of a cis-9, trans-10 isomerase. This step may occur via an ionic reaction as suggested by discovery of the cis-9, trans-10 isomerase structure and its mechanism of action in a study by Liavonchanka et al. (2006). In the next step, C18:2 isomers with trans-10, cis-12 double bonds and trans-10 C18:1 are formed. Reductions then occur until the carbon chain is completely saturated. McKain et al. (2010) demonstrated that B. fibrisolvens JW11 metabolize trans-10, cis-12 C18:2 to trans-10 C18:1, while B. proteoclasticus P-18 does not grow in the presence of trans-10, cis-12 C18:2, but grows in medium containing trans-9, trans-11 C18:2 to form C18:0. They also showed that $P$. acnes, a ruminal species which isomerizes linoleic acid to trans-10, cis-12 C18:2, does not further metabolize CLA isomers, and that $B$. fibrisolvens is able to metabolize small amounts of trans-10 C18:1. 


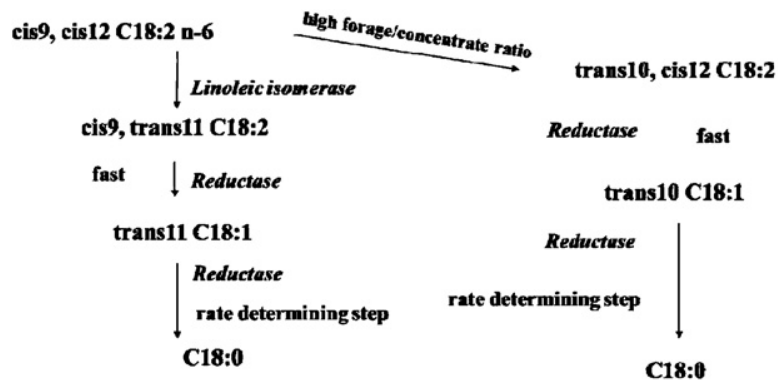

From Griinari and Bauman (1999), modified.

Fig. 3. Shift of linoleic acid biohydrogenation.

Trans-10, cis-12 CLA (Griinari et al., 1997, 1998; Griinari and Bauman, 1999) is involved in the milk fat depression (MFD) syndrome in ruminants. A study by Lock et al. (2007) suggested that the role of trans-10 C18:1 in MFD has to be reconsidered, and recent studies confirmed that this isomer may decrease mammary lipogenesis (Shingfield et al., 2009). Discrepancies in results among studies may be related to the dose-dependent effect, as Kadegowda et al. (2008) suggested that trans-6, trans-7 and trans-8 isomers of C18:1 might be more important than trans-10 C18:1 in MFD, and showed that trans-10, cis12 and trans-7, cis-9 CLA were the isomers most strongly negatively correlated to milk fat proportion, which implies that trans-7, cis-9 CLA has a possible role in MFD.

However several studies with dairy cows have identified other putative inhibitors of milk fat synthesis, such as trans-9, cis-11 and cis-10, trans-12 C18:2, although the synthesis mechanism has yet to be confirmed (Sæbø et al., 2005; Perfield et al., 2007). A strongly negative effect was detected for C18:1 trans-10 with respect CLA trans-9, cis-11 in dairy sheep (Cabiddu et al., 2009a). Wallace et al. (2007) incubated ruminal digesta with LA and obtained 9,11 CLA isomers with four possible combinations of structural geometry (cis/trans, trans/cis, trans/trans and cis/cis) and 10,12 CLA isomers with the geometry trans/cis and cis/cis. They also incubated pure cultures of B. fibrisolvens, Butyrivibrio proteoclasticum and P. acnes G449 isolated from ruminal digesta with LA in deuterium oxide-containing buffer and found the first two bacterial strains behaved similarly, producing mostly RA with small amounts of other 9,11 isomers, all labelled in C-13. No trace of 10,12 isomers occurred, except in cultures containing P. acnes which appeared to be specialized in producing 10, 12 CLA isomers. These results confirmed the high specificity of bacteria strains in synthesising CLA isomers, and that different mechanisms are involved. Wallace et al. (2007) proposed that LA-I acts by forming a radical intermediate where the $\mathrm{H}$ on C- 11 of LA is removed leaving a radical which is thermodynamically less favourable than a conjugated double bond system where the radical is located on C-13. Thus movement of the double bond from carbon atoms 12 and 13 occurs to maintain thermodynamic stability. A hydrogen atom is then removed from water in order to complete the reaction. With respect to formation of other 9,11 conjugated isomers, which are certainly less favourable in terms of energy with respect to the stability of RA radical intermediate, their synthesis probably occurs simultaneously with that of RA, and does not involve subsequent cis-trans or trans-cis isomerization of the cis-9 trans- 11 isomer.

The kinetic profile of CLA production differs among isomers, and is influenced by the inoculated substrate. The literature agrees in showing that minor isomers reach their maximum concentration in rumen liquor later than main isomers (Buccioni et al., 2006, 2008, 2009; Wallace et al., 2007).

\subsection{Conjugated linolenic acid isomers synthesis in the rumen}

BH intermediates of LNA were first observed by Reiser (1951), who found that after linseed oil was incubated with rumen sheep liquor, the LNA concentration decreased while the proportion of C18:2 and C18:1 increased. Shorland et al. (1955) subsequently observed that the depot fat of grazing ruminants had a FA profile low in LNA, which is the main FA in grass. Both these authors hypothesized that the rumen BH activity could play a fundamental role in reducing LNA reduction.

In the 1960s, studies of Ward et al. (1964), Wilde and Dawson (1966) and Kepler et al. (1966) were important milestones in our knowledge of rumen BH pathways. In 1967, Kepler and Tove purified cis-12, trans-11 isomerase from B. fibrisolvens and concluded that this enzyme might be active on LA and LNA isomers. The first step in biohydrogenation of LNA might be isomerization of the $\mathrm{C} 12$ bond, with the possible yield of intermediates cis-9, trans-11, cis-15 C18:3 and cis-9, trans-13, cis-15 C18:3.

This hypothesis was supported by identification in milk fat of two novel C18:2 isomers (i.e., trans-11, cis-15 C18:2 and cis-9, trans-13 C18:2) by Ulberth and Henninger (1994). Destaillats et al. (2005) characterized cis-9, trans-11, cis-15 C18:3 and cis-9, trans-13, cis-15 C18:3 and concluded that the presence of these FA in rumen fluid, which definitely originate in small quantities from rumen metabolism, confirm the pathway reported in Fig. 4. The same authors proposed "rumelenic acid" (RNA), "isorumelenic acid" and "vaccelenic acid" (VNA) as trivial names respectively for cis-9, trans-11, cis-15 C18:3 and cis-9, trans-13, cis-15 C18:3 and trans-11, cis-15, C18:2 by reference to RA, LNA and VA. Loor et al. (2004, 2005b) found a positive correlation between vaccelenic acid and $\alpha$-LNA levels in milk fat of dairy cows fed diets supplemented with linseed 


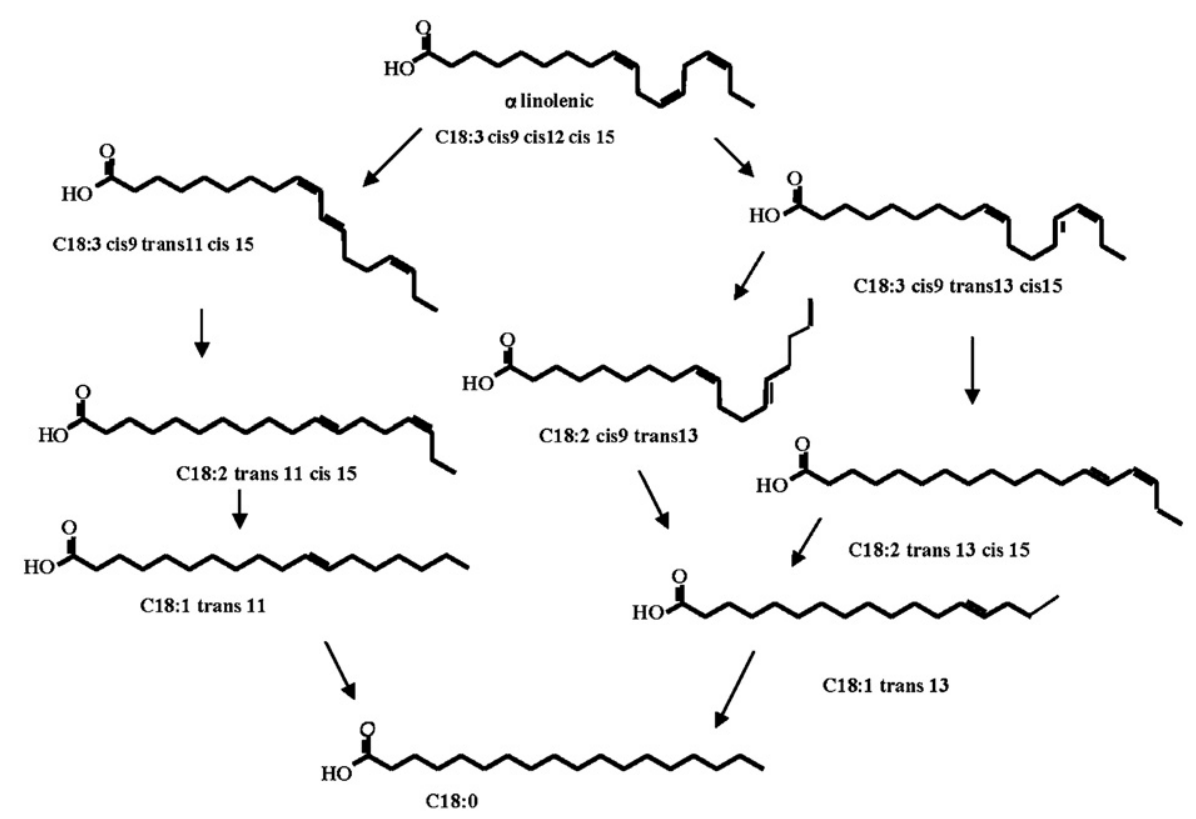

From Destaillats et al. (2005), modified.

Fig. 4. Ruminal biohydrogenation of linoleic and $\alpha$-linolenic acids.

or sunflower oil, which was confirmed by Wasowska et al. (2006) who showed that the concomitant presence of LNA and FO in ruminal fluid induces accumulation of RNA and VNA.

Griinari and Bauman (1999) proposed an alternative pathway of LA BH involving a cis-9, trans-10 isomerase which was analogous with the fate of LA when rumen fermentation involves ruminant low fibre diets (Fig. 5). It was postulated that the trans-10 intermediates may also play a role in MFD, and originate from the BH of LNA in a way similar to C18:2 isomers with a trans-10 double bond.

Loor et al. (2005a,b), completed an in vivo experiment on milk composition of cows fed a high concentrate diet (concentrate/forage ratio 650:350 on dry matter (DM basis)) supplemented with linseed oil at $30 \mathrm{~g} / \mathrm{kg}$ DM and found a drastic MFD associated with increased yield of trans-11, cis-15 C18:2, and trans isomers of C18:3, with a reduction in yield of C18:0 plus cis-9 C18:1. They noted, in particular, that high levels of dietary concentrate reduced milk fat yields compared to diets with a low concentrate content (i.e., $-90 \mathrm{~g} / \mathrm{d}$ of milk fat) and this decrease was worsened $-400 \mathrm{~g} / \mathrm{d}$ of milk fat when a low concentrate diet was supplemented with oil. These changes were accompanied by changes in the milk FA profile.

The trans-10 C18:1 content of milk fat as a consequence of feeding high levels of concentrate plus unsaturated oil accounted for $360 \mathrm{~g} / \mathrm{kg}$ of total trans-C18:1 in the study of Griinari et al. (1998), for $590 \mathrm{~g}$ in Piperova et al. (2000), for $670 \mathrm{~g}$ in Offer et al. (2001), for $430 \mathrm{~g}$ in Peterson et al. (2003), and for $240 \mathrm{~g}$ in Loor et al. (2005a). The different proportions of trans-10 C18:1 in milk fat in these studies may be due to the relatively low levels of dietary starch, $230 \mathrm{~g} / \mathrm{kg}$ DM, in Loor et al. (2005a) and because the diets were supplemented with polyunsaturated oils.

Offer et al. (1999), Donovan et al. (2000), Whitlock et al. (2002) and Shingfield et al. (2003) provide other evidence for a link between cis-11-C18:1 and FO-induced MFD. Dietary FO resulted in a 7-fold increase in the proportion of trans-9, cis-11-C18:2 in the rumen, which suggests that this FA may be a ruminal precursor of cis-11-C18:1.

\section{Lipid fractions in herbage, their manipulation and effects on PUFA ruminal biohydrogenation}

\subsection{Glycolipids}

The lipid composition of herbage (Figs. 6 and 7) is based on two classes of polar lipids which are usually associated with cellular membranes, and thus are also called membrane lipids (ML): glycolipids (GL) and phospholipids (PL). In contrast, the seed lipid profile mainly consists of non-polar lipids, triacylglycerides (TAG; Weenink quoted by Garton, 1960; Hawke, 1973). In GL lipids the head of the polar group is a carbohydrate, in PL it is based on phosphate, and TAG have no polar group. Herbage lipid accounts for 33, 135 and $832 \mathrm{~g} / \mathrm{kg}$ of total FA in TAG, FFA and ML respectively (Garton, 1960). Since TAG is an essential and crucial energy source during early stages of seedling growth, it is assumed that FA mobilization during seed germination is linked to plant tissue development. However leaf lipid FA are mainly based on GL, with a low energy content and a 25\% higher PUFA content than TAG, which is connected to GL's metabolic and structural roles in photosynthesis (Dörman and Benning, 2002). The higher levels of PUFA in plant leaves are mainly due to LNA, which is positively correlated with total lipid content (Crombie, 1958) and rate of photosynthesis Allakhverdiev et al. (2001), whose 


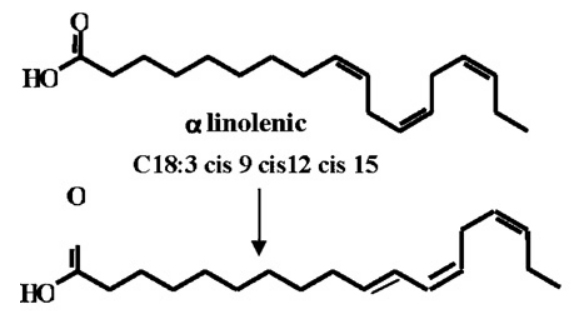

C18:3 trans10 cis12 cis 15

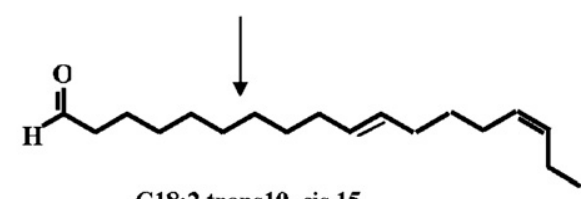

C18:2 trans10 cis 15

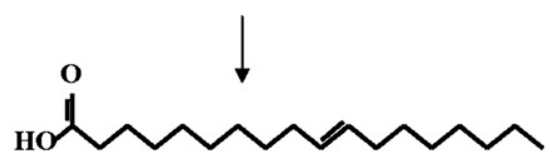

C 18:1 trans 10

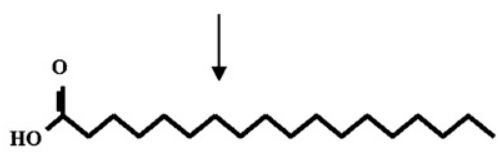

C18:0

From Griinari and Bauman (1999), modified.

Fig. 5. Alternative pathway of linolenic acid.

results confirm those of previous studies showing that water soluble carbohydrates tend to increase during daylight (Orr et al., 1997). Photosynthesis takes place in the thylakoid membrane which is a fluid mosaic containing proteins, lipids and pigments (Heinz and Siefermann-Harms, 1981). The thylakoid membrane contains about $400 \mathrm{~g}$ of lipids/kg DM and mainly consists of GL and PL, while lipids localized in leaf chloroplasts account for about 200-250 g/kg DM (Roughan and Batt, 1969;

Fat in seeds and oils

\section{Fat in forages}

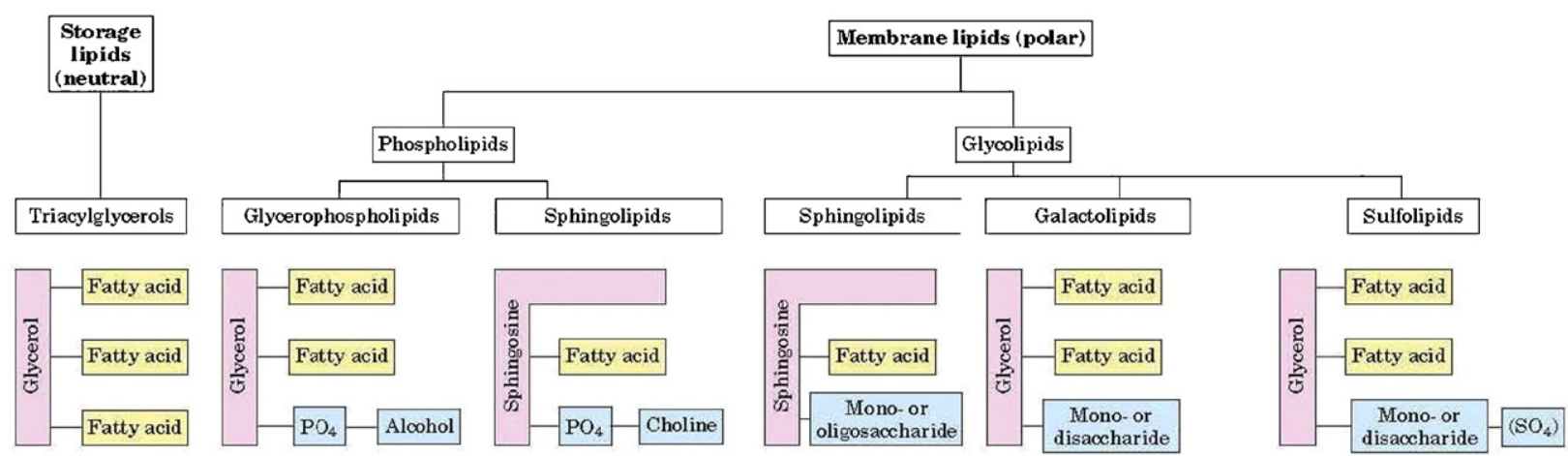

Fig. 6. Common types of storages and membrane lipids. All the lipid types shown have either glycerol or sphingosine as the backbone, to which are attached one or more long chain alkyl groups and a polar head group. In triacylglycerols, glycerophospholipids, galactolipids, and sulpholipids, the alkyl groups are fatty acids in ester linkage.

From Nelson and Cox (2004), modified. 

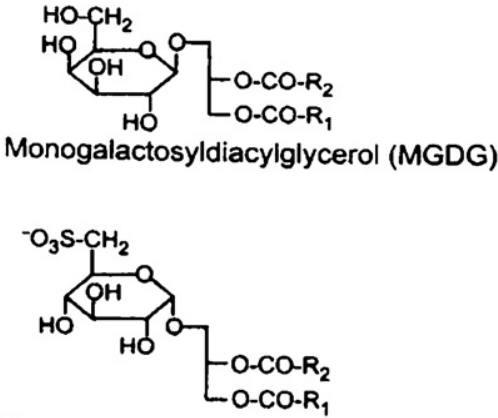

Sulfoquinovosyldiacylglycerol (SQDG)

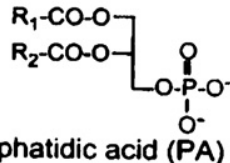

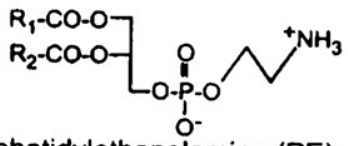

Phosphatidylethanolamine (PE)

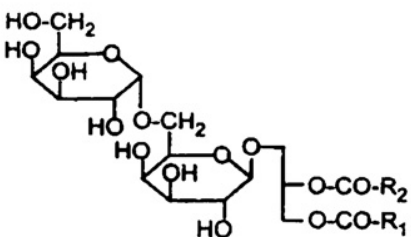

Digalactosyldiacylglycerol (DGDG)<smiles>[R]OC(=O)OCC(CO[P+]([O-])([O-])OCC(O)CO)O[R20]</smiles>

Phosphatidylglycerol (PG)

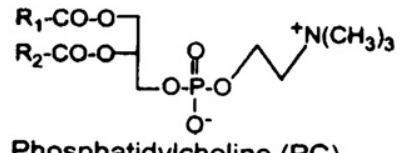

Phosphatidylcholine (PC)

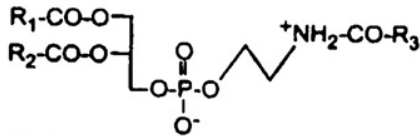

N-Acyl-Phosphatidylethanolamine (NAPE)

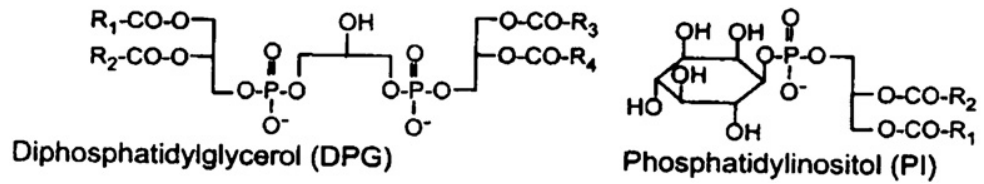

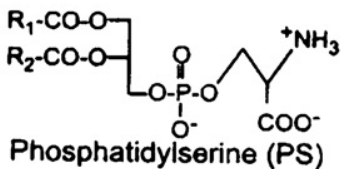

Phosphatidylserine (PS)

Fig. 7. Structure of membrane glycerolipids. In higher plants the non-phosphorous glycolipids MGDG, DGDG and SQDG are the predominant lipid classes in chloroplast. Phospholipids (i.e., PC, PE, and PG) are abundant in extraplastidic membranes. Additional phospholipids (i.e., PA, PS, NAPE DPG, and PI) are minor components of plant membranes and are restricted to specific organelles or accumulate under only some environmental conditions.

From Dörman (2005), modified.

Table 1

Lipid composition of ryegrass leaves ( $\mathrm{g} / \mathrm{kg}$ of lipids).

\begin{tabular}{|c|c|c|c|c|c|c|c|}
\hline \multicolumn{2}{|l|}{$\begin{array}{l}\text { Glycolipids } \\
\text { ( } 308 \mathrm{~g} / \mathrm{kg} \text { of lipids) }\end{array}$} & \multicolumn{2}{|c|}{$\begin{array}{l}\text { Phospholipids } \\
\text { ( } 368 \mathrm{~g} / \mathrm{kg} \text { of lipids) }\end{array}$} & \multicolumn{2}{|l|}{$\begin{array}{l}\text { Simple lipids } \\
\text { ( } 234 \mathrm{~g} / \mathrm{kg} \text { of lipids) }\end{array}$} & \multicolumn{2}{|c|}{$\begin{array}{l}\text { Pigment ( } 92 \mathrm{~g} / \mathrm{kg} \text { of } \\
\text { lipids) }\end{array}$} \\
\hline DGDG & 105 & PE & 44 & Diglycerides & 88 & Chlorophyls & 141 \\
\hline MGDG & 105 & PC & 35 & Fatty acids & 84 & Carotenes & 34 \\
\hline SQDG & 44 & PI & 13 & Sterols & 32 & Tocopherols & 3 \\
\hline
\end{tabular}

Component fatty acids $(415 \mathrm{~g} / \mathrm{kg}$ of lipids)

\begin{tabular}{llllll}
\hline C16:0 & C18:0 & C18:1 & C18:2 & Other \\
\hline 159 & 10 & 23 & 120 & 620
\end{tabular}

Adapted and calculated from Hudson and Warwick (1977).

PC=phosphatidylcholine; $\quad$ PE= phosphatidylethanolamine; $\quad$ PG = phosphatidylglycerol; $\quad$ PI=phosphatidylinositol; $\quad$ PS=phosphatidylserine; DPG = diphosphatidylglycerol MGDG = monogalactosyldiacylglycerol; DGDG = digalactosyldiacylglycerol; SQDG = sulphoquinovosyldiacylglycerol.

Hawke, 1973; Heinz and Siefermann-Harms, 1981; Jarrige et al., 1995). Depending on their function, TAG synthesis takes place on the endoplasmic reticulum (ER) while that of polar lipids occurs in the thylakoid (Gounaris et al., 1986; Fig. 8). Most GL in fresh forage (Table 1) are monogalactosyldiacylglicerol (MGDG) and digalactosyldiacylglycerol (DGDG), also called galactolipids (GA) and were first discovered by Carter et al. (1956) and subsequently confirmed by Weenink (1961). 


\section{En}

ENDOPLASMIC

RETICULUM

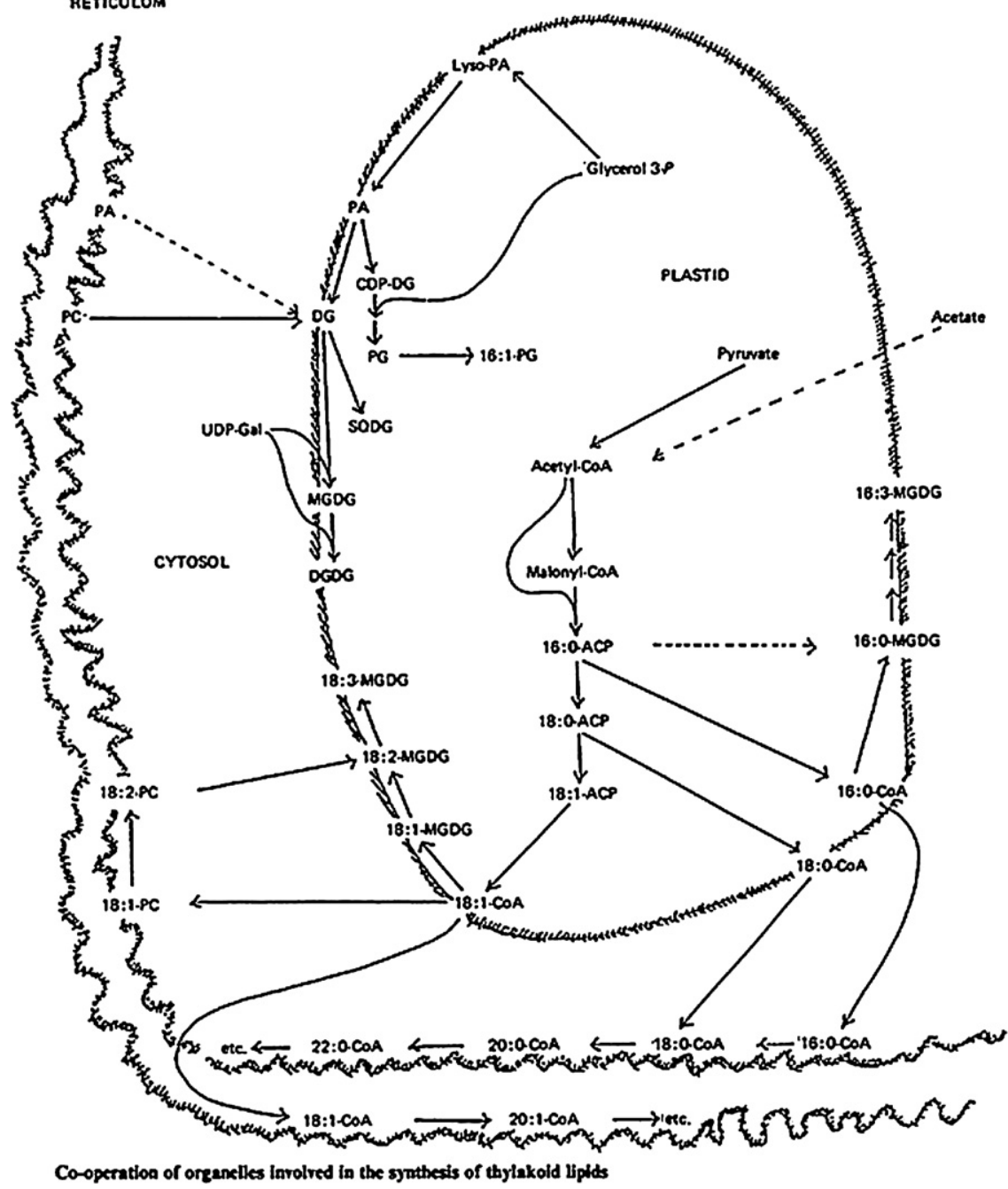

Fig. 8. Synthesis de novo of palmitate, stearate and oleate takes place in the plastid stroma. The relative contribution of plastid or extra-plastid generated diacylglycerol varies among plant species. The elongation reactions for formation of very long chain fatty acids are shown here with acyl-CoA substrates, but other substrates may be used in different tissues. For clarity, routes of fatty acid and acyl lipid synthesis are shown separately, but they are interdependent to some extent.

From Gounaris et al. (1986), modified.

Shorland (1961) and Weenink (1962) later found that the FA profile of GL were almost entirely composed of LNA (Table 2; O'Brien and Benson, 1964; Roughan and Batt, 1969) and that the neutral fatty acid (NFA) and FFA fractions had different FA profiles (Table 3). Plant sulpholipids (SL) are specifically associated with the photosynthetic membranes of higher plants, where their structure is based on 1,2 diacylglicerol-3-(6-sulpho- $\alpha$-D-quinovopyranosyl)-sn glycerol (SQDG; Figs. 6 and 7). Plant SL are the third component of GL fresh herbage lipids after GA and sphingolipids with less LA as well as more palmitic (PA) and SA than MGDG and DGDG (O'Brien and Benson (1964), in agreement with Roughan and Boardman (1972) who postulated the higher ratio of SFA in SL. The SQDG level is about $40-50 \mathrm{~g} / \mathrm{kg}$ of total lipid in plant leaves (Roughan and Boardman, 1972; Hudson and Warwick, 1977; Table 4).

Glyco-sphingolipids (SPH) have a sphingosine chain as their backbone (Figs. 6, 9, 10), to which are attached a FA and one or more carbohydrates as the polar head group (Lehninger, 1979). In plant cells, SPH are mainly glucosylceramide (GSC; cerebrosides) and glycosylated inositol phosphoryl-ceramides (Fig. 11), with higher SFA content and lower levels of cis-9 


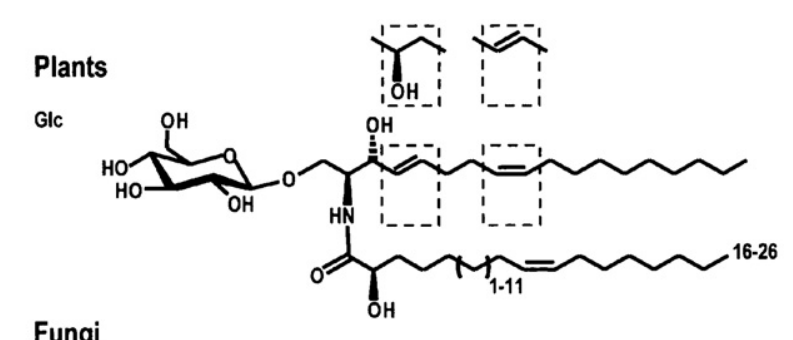

Fungi
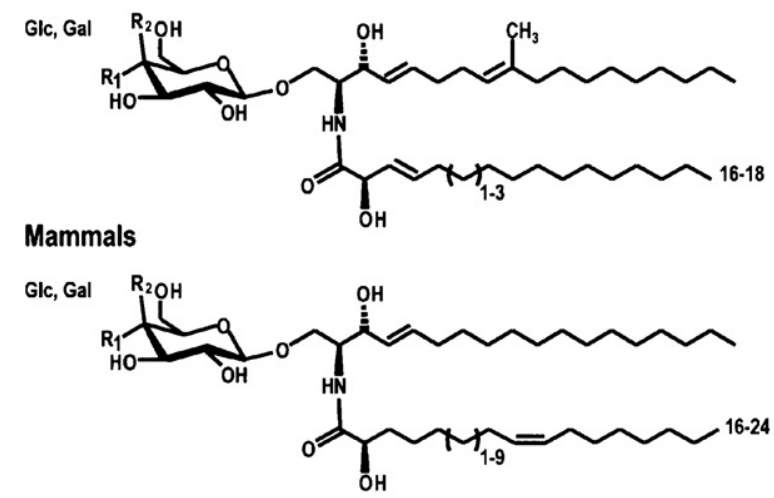

Fig. 9. Glycosylceramides from plants, fungi and mammals. The ceramide backbones of glucosylceramides from plants (at the top) show great variety. Their sphingoid bases carry three possible modifications being: hydroxylation or trans desaturation at C-4, and cis or trans desaturation at C-8, the combination of which results in seven frequent plant sphingoid bases. These sphingoid bases are linked to more than ten a-hydroxy fatty acids varying in chain length and $n-9$ desaturation. In contrast to plants, glucosyl- and galactosylceramides from fungi (middle) have a characteristic fungal consensus structure with only a few structural variations.

From Warnecke and Heinz (2003), modified.

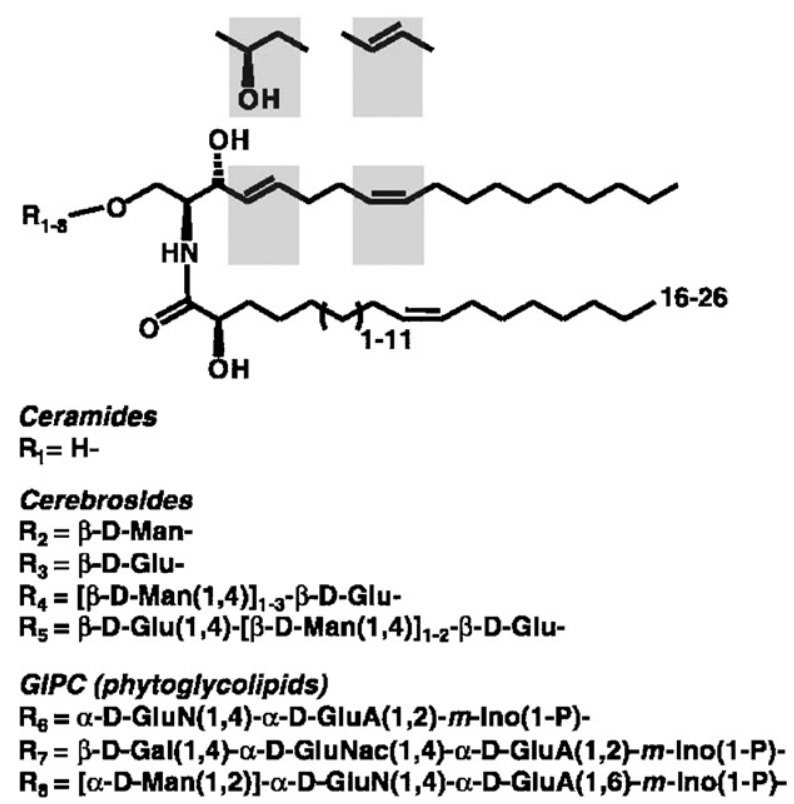

Fig. 10. Structures of ceramide glycosides from plants. The ceramide backbones of plant sphingolipids have large variability. Their long-chain bases carry four possible modifications (on grey background), which are hydroxylation or (E)-desaturation at C-4, and (E)- or (Z)-desaturation at C-8 resulting in seven frequent long chain bases.

From Sperling and Heinz (2003), modified. 
Table 2

Fatty acid composition ( $\mathrm{g} / \mathrm{kg}$ of fatty acids) in plant lipids.

\begin{tabular}{lll}
\hline & MGDG & DGDG \\
\hline $\mathrm{C} 14: 0$ & $\operatorname{tr}$ & $\operatorname{tr}$ \\
$\mathrm{C} 15: 0$ & $\operatorname{tr}$ & - \\
$\mathrm{C} 16: 0$ & 24.9 & 128.7 \\
$\mathrm{C} 16: 1$ & $\operatorname{tr}$ & $\operatorname{tr}$ \\
$\mathrm{C} 17: 0$ & $\operatorname{tr}$ & 6.8 \\
$\mathrm{C} 18: 0$ & 2.1 & 33.7 \\
$\mathrm{C} 18: 1$ & 3.1 & 4.1 \\
$\mathrm{C} 18: 2$ & 17.2 & 8.1 \\
$\mathrm{C} 18: 3$ & 952.8 & 818.7 \\
\hline
\end{tabular}

Adapted from O'Brien and Benson (1964).

MGDG = monogalactosyldiacylglycerol; $\mathrm{DGDG}=$ digalactosyldiacylglycerol; $\mathrm{tr}=$ trace .

$-=$ not reported in the original publication.

Table 3

Fatty acid composition of red clover lipid fractions ( $\mathrm{g} / \mathrm{kg}$ of fatty acids).

\begin{tabular}{lcl}
\hline & Galactolipids & Hexane soluble lipids \\
\hline C8:0 & - & 2.2 \\
C10:0 & - & $\operatorname{tr}$ \\
C12:0 & - & 5.4 \\
C14:0 & - & 19.2 \\
C16:0 & 21.2 & 142.3 \\
C18:2 & 19.2 & 60.1 \\
C18:3 & 959.6 & 770.7 \\
\hline
\end{tabular}

Adapted and calculated from Weenink (1961).

$-=$ not reported in the original publication.

Table 4

Lipid composition of plant cell membranes (moles/kg total lipids).

\begin{tabular}{|c|c|c|c|c|c|c|c|c|c|c|c|}
\hline & PC & PE & PG & PI & PS & DPG & MGDG & DGDG & SQDG & Sterols & Glyco-sphingolipids \\
\hline \multicolumn{12}{|l|}{ Endomembranes } \\
\hline Reticulum + Golgi & 434.8 & 232.6 & 60 & 60 & 30 & - & - & - & - & 41.5 & - \\
\hline Tonoplast & 152.8 & 152.8 & 20 & 59 & 20 & - & - & - & - & 144.3 & 121.7 \\
\hline $\begin{array}{l}\text { Plasma membrane } \\
\text { Chloroplast }\end{array}$ & 83.6 & 93.2 & 15 & 16 & 11 & - & - & - & - & 56 & 63 \\
\hline Outer membrane & 320 & & 100 & 50 & - & - & 170 & 300 & 60 & - & - \\
\hline Inner membrane & & & 90 & 10 & - & - & 550 & 300 & 50 & - & - \\
\hline Thylakoids & & & 70 & 10 & - & - & 580 & 270 & 70 & - & - \\
\hline \multicolumn{12}{|l|}{ Mitochondria } \\
\hline Outer membrane & 520 & 220 & 30 & 100 & - & - & - & - & - & 130 & - \\
\hline Inner membrane & 370 & 330 & 20 & 40 & - & 110 & - & - & - & 130 & - \\
\hline
\end{tabular}

Adapted and calculated from Jouhet et al. (2007).

$-=$ not reported in the original publication.

$\mathrm{PC}=$ phosphatidylcholine; $\quad \mathrm{PE}=$ phosphatidylethanolamine; $\quad \mathrm{PG}=$ phosphatidylglycerol; $\quad \mathrm{PI}=$ phosphatidylinositol; $\quad$ PS = phosphatidylserine; $\mathrm{DPG}=$ diphosphatidylglycerol MGDG = monogalactosyldiacylglycerol; DGDG = digalactosyldiacylglycerol; SQDG = sulphoquinovosyldiacylglycerol.

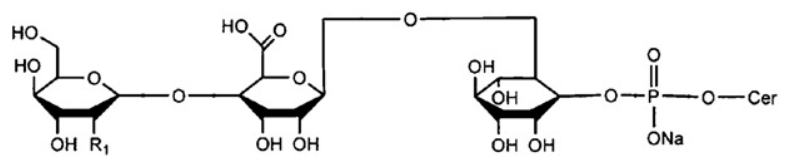

Fig. 11. A glycolipids basal structure (glycosylinositolphosphoceramide) one the simplest lipids in higher plants, the most abundant sphingolipid in the membranes of leaves of tomato and soybean.

From Markham et al. (2006), modified.

22-26-carbon monounsaturated FA. Thus while inositol-containing SPH are found only in plants and fungi, GSC is the only SPH which plants, fungi and animals have in common (Warnecke and Heinz, 2003).

\subsection{Phospholipids}

Analytical research by Carter et al. (1969), later extended by Hsieh et al. (1978), revealed that glycophosphosphingolipids (GPSL) contain $\mathrm{N}$-acetyl-glucosamine and an inositol bonded via a phosphodiester link to a ceramide and via a glycosidic link to a chain of carbohydrates of variable composition, sugars such as mannose, arabinose and/or fructose (Bromley et al., 


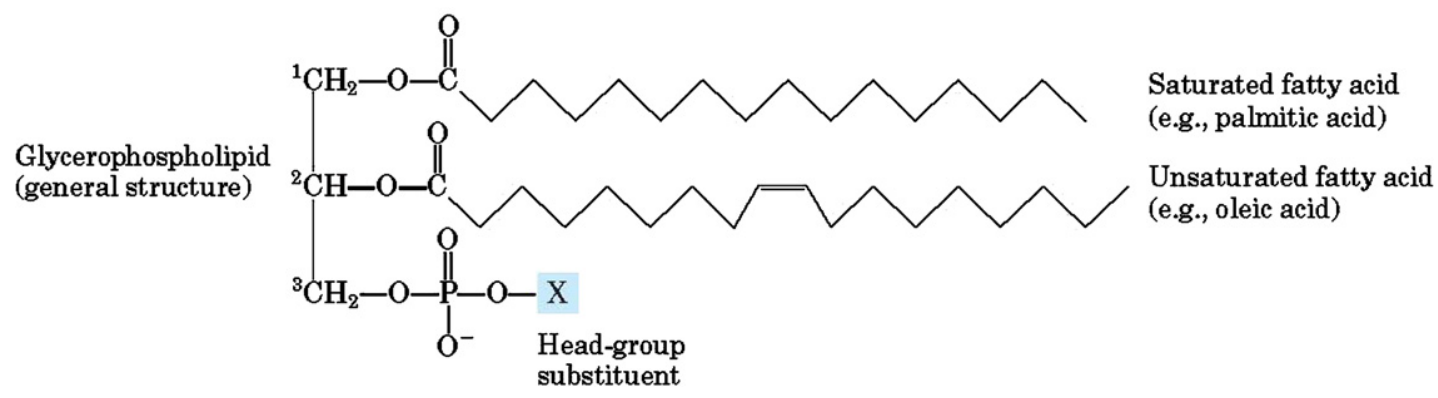

Fig. 12. The common glycerophospholipids are diacylglycerols linked to head-group alcohols through a phosphodiester bond. Head group substituents could be ethanolamine, choline, serine, glycerol, myo-inositol 4,5 biphosphate or phosphatidyl-glycerol.

From Nelson and Cox (2004), modified.

2003). The main sphingoid bases in plants are dihydrosphingosine (DHS) and phytosphingosine (PHS) of which it has been estimated that there are 300-400 molecular species (Hannun et al., 2001). The simplest forms of a wide range of structures are in yeasts and fungi. More complex forms are in protozoa and in plants, (Fig. 9). GPSL makes up $1 \mathrm{~g} / \mathrm{kg}$ of DM in leaves, while LA and LNA acids are 92 and $720 \mathrm{~g} / \mathrm{kg}$ of total FA, respectively. As with GL, where the backbone consists of glycerolipids, these lipids are called glycerophospholipids (GPL: Fig. 12) while, if the backbone is a sphingosine lipid, they are called sphingolipids (SHL).

GPL are derived from phosphatidic acid and, in all these compounds, the head group is joined to glycerol through a phosphodiester bond. The usual level of phospholipids in forage is about $260 \mathrm{~g} / \mathrm{kg}$ of ether extract, corresponding to $22 \mathrm{~g} / \mathrm{kg}$ of DM (Weenink, 1962) with phospatidyl cholin being the main component ( $450 \mathrm{~g} / \mathrm{kg}$ of total PL), followed by phospatidylglycerol (300 g/ kg), phospatidylethanolamine (180 g/ kg) and phosphatidylinositol (100 g/ kg), as reported by Roughan and Batt (1969). However there are differences in the literature (Hudson and Warwick, 1977), probably because the PL composition was obtained from different forages species and analysed using different methods. The FA profile of GPL has higher levels of PA, and lower levels of LA and LNA ( $560 \mathrm{~g} / \mathrm{kg}, 210 \mathrm{~g} / \mathrm{kg}, 90 \mathrm{~g} / \mathrm{kg}$ of FA, respectively; Weenink (1962), with forage species probably having an effect (Table 5; Roughan and Boardman, 1972).

Overall, in herbage samples the lipid fractions associated with different FA profiles may influence ruminal LP and BH. Indeed GL disappeared very quickly from the rumen of sheep fed grass herbage and, after $8 \mathrm{~h}$ of ruminal incubation, MGDG hydrolysis was twice that of DGDG (Dawson et al., 1974). It is also well known that LNA in plants is more common in the polar fraction than in FFA or TAG (826 and $470 \mathrm{~g} / \mathrm{kg}$ of FA, respectively) while LA is more common in TAG than FFA or the polar fraction $(230,174,50 \mathrm{~g} / \mathrm{kg}$ of FA, respectively). This distribution of plant lipids helps explain the higher transfer efficiency of PUFA to meat and milk of ruminants fed fresh forage rather than oils and oilseeds (Doreau and Ferlay, 1994; Dhiman et al., 1999; Bernard et al., 2009; Lee et al., 2009a). Indeed Dawson et al. (1974) hypothesized that the BH rate of linolenic acid is lower when it comes from MGDG and DGDG rather than FFA. Recent results from Cabiddu et al. (2010) pointed out for the first time in the bibliography that the BH rate of LNA was negatively correlated with ML fraction level (Fig. 13) in two forage species at two different phenological stages, whereas Vicia sativa had higher values of ML, LNA (Fig. 14) than Trifolium incarnatum.

\section{Plant endogenous factors which influence fatty acid profile, PUFA ruminal lipolysis and biohydrogenation}

Variations in the lipid composition of fresh forages are due to many factors, including plant species (Crombie, 1958; Shorland, 1961; Roughan and Batt, 1969; Melo et al., 1995; Addis et al., 2005; Cabiddu et al., 2005) cultivars within species

Table 5

Fatty acid composition ( $\mathrm{g} / \mathrm{kg}$ total fatty acids) on lipid fractions from Pea and Bean leaves.

\begin{tabular}{|c|c|c|c|c|c|c|c|c|c|c|c|c|}
\hline & \multicolumn{6}{|l|}{ Pea } & \multicolumn{6}{|l|}{ Bean } \\
\hline & C16:0 & C16:1 & C18:0 & C18:1 & C18:2 & C18:3 & C16:0 & C16:1 & C18:0 & C18:1 & C18:2 & C18:3 \\
\hline MGDG & 26.7 & 0 & $\mathrm{tr}$ & tr & 90.8 & 881.5 & 26.6 & 0 & $\operatorname{tr}$ & $\operatorname{tr}$ & 48.5 & 924.9 \\
\hline DGDG & 167.8 & 0 & 82.7 & $\mathrm{tr}$ & 81.6 & 668.0 & 168.0 & 0 & 41.4 & $\mathrm{tr}$ & 20.4 & 770.2 \\
\hline PC & 219.1 & 0 & 74.0 & 31.5 & 448.0 & 227.5 & 215.1 & 0 & 41.5 & 10.3 & 296.6 & 436.6 \\
\hline PE & 205.2 & 0 & 62.1 & $\mathrm{tr}$ & 510.0 & 222.8 & 253.3 & 0 & 31.2 & $\operatorname{tr}$ & 348.8 & 366.7 \\
\hline PG & 538.1 & 0 & 42.6 & 21.2 & 210.2 & 187.8 & 753.7 & 0 & 76.0 & $\mathrm{tr}$ & 32.1 & 138.2 \\
\hline PI & 418.3 & 0 & 73.8 & $\mathrm{tr}$ & 291.1 & 216.8 & 548.3 & 0 & 74.7 & $\operatorname{tr}$ & 126.3 & 250.7 \\
\hline SL & 340.1 & 0 & 104.8 & $\mathrm{tr}$ & 291.1 & 216.8 & 428.5 & 0 & 105.6 & $\mathrm{tr}$ & 72.9 & 392.9 \\
\hline
\end{tabular}

Adapted and calculated from Roughan and Boardman (1972).

$\operatorname{tr}=$ trace.

MGDG = monogalactosyldiacylglycerol; $\quad$ DGDG = digalactosyldiacylglycerol; $\quad P C=$ phosphatidylcholine

$\mathrm{PG}=$ phosphatidylglycerol; $\mathrm{PI}=$ phosphatidylinositol; $\mathrm{SL}$ = sulpholipid (sulphoquinovosyl diglyceride). 

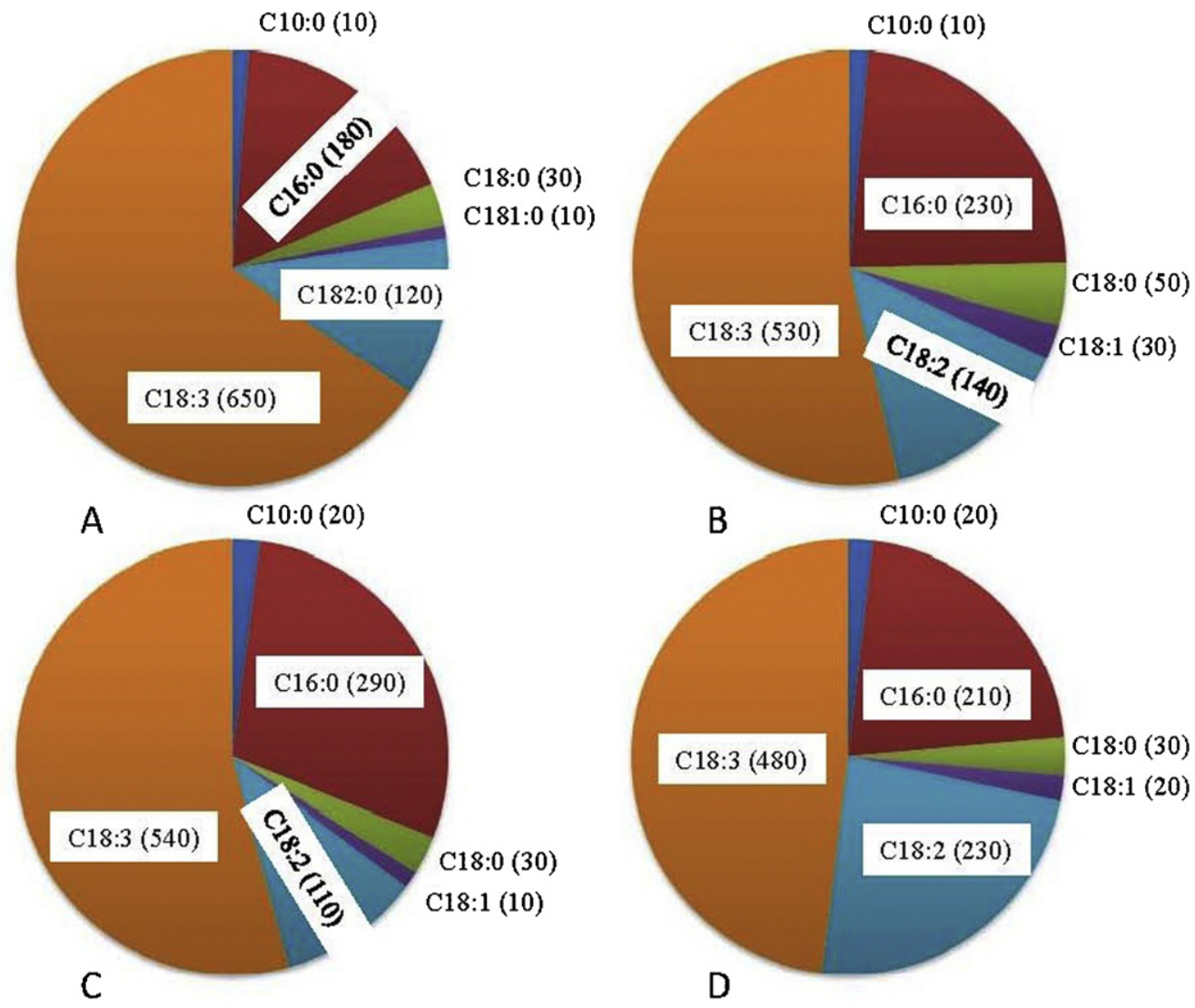

Fig. 13. Fatty acid distribution (values in brackets are expressed as $\mathrm{g} / \mathrm{kg}$ of fatty acid methyl esters) of plants where (a) and (b) are FA profiles of membrane lipids of Vicia sativa at vegetative and reproductive stages, respectively, and (c) and (d) are FA profiles of membrane lipids of Trifolium incarnatum at vegetative and reproductive stages.

From Cabiddu et al. (2010), adapted.

(Quartacci et al., 1995; Elgersma et al., 2003; Cabiddu et al., 2009c), plant age and phenological stage (Cabiddu et al., 2009c), position of the leaves on the plant (Krebsky et al., 1996) level of sensitivity to drought (Quartacci et al., 1995), and grazing or cutting management (Dewhurst et al., 2001). Nichols (1963) reported that lipid classes are found in different proportions in different plant organs (i.e., leaves versus stems), with leaves having a higher GL content than stems. Stems are very low in TGA, and SL compared to leaves where the polar fractions are the main lipid component.

Several authors (e.g., Molle et al., 2004) have reported that diets of grazing ruminants are usually richer in leaves than stems leading to the assumption that leaves are the main dietary source of lipid for BH, and this is supported by the strong relationship between the leafiness of grazed forages and the vaccenic acid content in milk from grazing sheep (Cabiddu et al.,

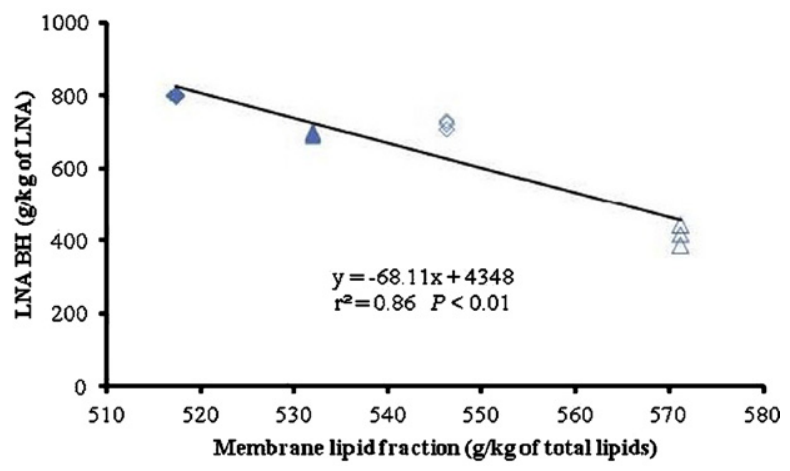

Fig. 14. Relationship between membrane lipid fraction and linolenic acid (LNA) ruminal biohydrogenation in herbage samples of Vicia sativa (rumble symbol) and Trifolium incarnatum (triangle symbol) at vegetative (open symbols) and reproductive (solid symbols) stages.

From Cabiddu et al. (2010), adapted. 
Table 6

Fatty acid composition ( $\mathrm{g} / \mathrm{kg}$ fatty acids) on lipid fractions of red clover leaves.

\begin{tabular}{|c|c|c|c|c|c|c|c|c|c|c|c|c|}
\hline & C12:0 & C14:0 & C14:1 & C15:0 & C16:0 & C16:1 & C17:0 & C18 br & C18:0 & C18:1 & C18:2 & C18:3 \\
\hline Triglycerides & 7.1 & 109.5 & - & 2.9 & 174.6 & 6.0 & $\operatorname{tr}$ & $\operatorname{tr}$ & 28.4 & 37.4 & 407.2 & 339.3 \\
\hline Phospholipids & - & 3.6 & - & $\mathrm{tr}$ & 566.2 & 28.2 & $\operatorname{tr}$ & $\operatorname{tr}$ & 33.8 & 40.2 & 229.7 & 100.3 \\
\hline Galactosyl glycerides & - & 0.8 & - & - & 16.6 & $\mathrm{tr}$ & - & - & 3.1 & 6.1 & 25.2 & 948.2 \\
\hline
\end{tabular}

Adapted and calculated from Weenink (1962).

$\operatorname{tr}=$ trace.

$-=$ not reported in the original publication.

br $=$ branched.

2004). The lipid fraction in leaves is not randomly distributed, with $400 \mathrm{~g} / \mathrm{kg}$ of leaf lipids in chloroplasts, with GL restricted to plastid membranes and PL, the main components of extraplastidic membranes (Table 4). GL and PL constitute $600 \mathrm{~g} / \mathrm{kg}$ of leaf lipids, although this allocation changes when chloroplasts ( 745 versus $255 \mathrm{~g} / \mathrm{kg}$ of lipid for GL and PL, respectively) or cytoplasms (840 versus $150 \mathrm{~g} / \mathrm{kg}$ of lipids for PL and SL, respectively) are considered.

As reported in Table 6, LA and LNA levels differ among lipid classes (Schwertner and Biale, 1973), with a higher level of LA in TGA and in PL (373 and $250 \mathrm{~g} / \mathrm{kg}$ of total FA, respectively), whereas LNA is more common in GL (950 g/ $/ \mathrm{kg}$ of total FA; Weenink, 1961). It is of interest that the different distribution of LA and LNA in plant organs, and different FA profile in these lipid classes, may influence the fate of FA to LP and oxidation loss. Almost four decades have passed since the first results from Faruque et al. (1974) suggested that hydrolysis of TGA and GA from grass was due primarily to plant enzyme activity, such as galactolipases which catalyse MGDG and DGDG, phospholipases which catalyse GPL and sulpholipases which catalyse SL. In recent years several studies have been completed to clarify the pathways of endogenous lipolytic systems in plants (Lee et al., 2009b; Van Ranst et al., 2011). Since fresh forage can be a rich source of $\omega$-3 FA and CLA precursors, considerable effort has been made to develop efficient enrichment strategies for these FA in animal products using feeding strategies. In the last decade the large amount of research on plant endogenous factors involved in ruminal lipid metabolism assumed that fresh forage can play an important role in making ruminant products less expansive, healthier and their production more environmentally sustainable. A preliminary study by Lee et al. (2003) showed that endogenous lipolytic activity had a detrimental (-25\%) effect on ML content, and was associated with a $180 \%$ increase in FFA, which was demonstrated by incubating leaf blades of Lolium perenne and Trifolium pratense with buffer without rumen liquor. Endogenous lipolysis in grass forage species reached a plateau after $2 \mathrm{~h}$ of in vitro incubation while this plateau was reached very slowly in legumes with a resulting detrimental effect on the LA and LNA BH ratio of the legumes (Dewhurst and Lee, 2004). Lee et al. (2003) hypothesized that this action might be due to polyphenol oxidase (PPO), which had been previously shown to have an inhibiting effect on endogenous plant proteolysis (Jones et al., 1995). As reported by several authors, PPO is a copper metalloprotein which functions in the presence of oxygen, and is able to reduce LP in red clover through deactivation of lipolytic enzymes and/or through formation of protein-phenol-lipid complexes. When the PPO enzyme from red clover was incubated with a wide range of ortho-diphenols in the presence of oxygen, there was rapid conversion from the latent to the active form of PPO (Lee et al., 2008a), a conversion inhibited by adding ascorbic acid, suggesting that this mechanism requires formation of ortho-quinones. Other factors which influence the efficacy of PPO, to produce phenol-bound protein and/or PPO activation includes oxygen concentration, the phenological stage of the plant and the plant's NDF content (Lee et al., 2009b; Cabiddu et al., 2011).

Polyphenol oxidase increases lipid protection from endogenous lipolytic activity and rumen BH by 11-22\% (Lee et al., 2007b, 2008a), to a maximum of 33\% (Lee et al., 2006, 2007b). However it cannot be definitely concluded from these results whether protection is due to lipase inhibition, or if lipid protection is due to protein-phenol and/or lipid-phenol complexes (Lee et al., 2010).

Several studies by Lee et al. (2003, 2004, 2006, 2007b, 2008a, 2009b, 2010) showed that LP is mediated by plant endogenous lipases up to $50 \%$. During grazing, the feed bolus is exposed to oxygen by rumination and the PPO system is activated (Lee et al., 2009b). In a simulated rumen environment, the extent of endogenous LP after $24 \mathrm{~h}$ of incubation ranges from $650 \mathrm{~g} / \mathrm{kg}$ of lipids for cocksfoot to $820 \mathrm{~g} / \mathrm{kg}$ for red clover (Lee et al., 2006, 2008a, 2011). Bauchart et al. (1990b) found that lipid hydrolysis was much higher in diets enriched with lipids than in diets without lipid supplements. Several authors also noted that LP in the rumen needs a pH of 6-7 (Tamminga and Doreau, 1991), as does the rumen microbial population and their lipolytic activity (Song et al., 2008). When in vivo results from ruminants fed red clover silage, with higher PPO activity, were compared with those fed grass silage with lower PPO activity, it was found that red clover transfers C18:2 and C18:3 from feed to milk more efficiently than grasses (Dewhurst et al., 2003; Lee et al., 2009a; Moorby et al., 2009). Similar results have been reported when red clover was compared with white clover (Steinshamn, 2010), thereby supporting the hypothesis that PPO offers protection from plant endogenous lipolysis and from ruminal BH. As reported by several authors, many factors are involved in this process because, in such cases, red clover may indirectly influence ruminal lipolysis and biohydrogenation through a shift in the ruminal microbial population (Huws et al., 2010), or by lipid encapsulation in protein-phenol matrices (Lee et al., 2010). Because ruminal lipolysis and biohydrogenation are also indirectly influenced by the rumen passage rate, there may be an association between PPO lipolysis protection, and the increase in passage rate, as reported by Vanhatalo et al. (2007) in white clover. There may be a lack of consistency between the PPO, passage rate and lipid encapsulation theories. Thus we suggest that lipolysis and BH are directly influenced by the association of PPO, 
passage rate, lipid incapsulation, and other plant secondary metabolites, and this may sometimes lead to results which are apparently contradictory. For example, despite red clover having higher levels of PPO than white clover, Van Dorland et al. (2008) found that white clover has a slight advantage over red clover, especially for leading to higher LNA, EPA and DHA levels in milk. Actually these results are not contradictory to the ones by Lee and collaborators, who pointed out the PPO effect on LP and BH, because white clover has numerous secondary plant metabolites (Carlsen and Fomsgaard, 2008), such as phenols, which influence the ruminal microbial ecosystem as reported by Cabiddu et al. (2010). Research needs to be completed on how the interactions between PPO, ruminal passage rate, lipid incapsulation and PSM influence lipolysis and biohydrogenation, and their respective hierarchy.

Another factor which affects LP is forage DM content, especially for ryegrass, where a reduction in LP ( $-44 \%$; P<0.01) occurred when DM increased from 300 to $500 \mathrm{~g} / \mathrm{kg}$ (Van Ranst et al., 2009). The increase in ryegrass DM implies a reduction in silage fermentation and thus reduced ML exposure to lipase (Van Ranst et al., 2009). By contrast, this effect did not occur for clover, probably due to the negative effect of protein bound phenols (PBP) on microbial lipase (Van Ranst et al., 2009). Lee et al. (2010) showed that, in spite of the increase in PBP after wilting, endogenous lipolysis is not affected but, after in vitro incubation, LP was lower in wilted cocksfoot than tall fescue, due to the inhibiting effect of PBP on ruminal microbial activity (Lee et al., 2011). The DM content (i.e., wilting effect) may have a detrimental additive effect on lipolysis to a more damaging degree (Van Ranst et al., 2010).

Biohydrogenation is heavily influenced by PSM, which includes PPO, fatty acid oxidation (FAOP) and tannins (Lee et al., 2007a; Cabiddu et al., 2009b, 2010). Several reports on the relationship between tannin and rumen metabolism mention the negative effects of modulation of protein and fibre degradation on development of the rumen microflora. However little information is available on effects of polyphenolic compounds, such as LA-I, on rumen enzyme activity (Cabiddu et al., 2009b, 2010). However Vasta et al. (2009a,b) reported that tannins do not interfere with LA-I, but do interfere with microbial proliferation. Thus tannins do not inhibit the activity of microbial enzymes, but shift the composition of the rumen microbial population.

\section{Odd and branched chain fatty acids: a new frontier in the study of rumen microbial metabolism}

Ruminal bacteria contain 50-90 g/kg (DM) lipids, with PUFA and odd and branched chain fatty acids (OBCFA) representing $40 \mathrm{~g} / \mathrm{kg}$ and $50 \mathrm{~g} / \mathrm{kg}$ of total FA, respectively (Kaneda, 1991; Mansbridge and Blake, 1997). OBCFA from rumen microorganisms mainly consists of iso $\mathrm{C} 13: 0$, anteiso $\mathrm{C} 13: 0$, iso $\mathrm{C} 14: 0$, iso $\mathrm{C} 15: 0$, anteiso $\mathrm{C} 15: 0$, iso $\mathrm{C} 16: 0$, anteiso $\mathrm{C} 16: 0$, iso $\mathrm{C} 17: 0$, anteiso C17:0 (Vlaeminck et al., 2004a, 2006a). There is increasing interest in milk OBCFA as potential diagnostic tools of rumen function because determining milk OBCFA is non-invasive, and thus more acceptable than current in vivo techniques which usually involve use of ruminally fistulated animals (Vlaeminck et al., 2006a; Bessa et al., 2009). Rumen bacteria OBCFA are mainly C15:0 isomers, with 590-670 g/kg of total OBCFA (Vlaeminck et al., 2004b). Among dietary components, starch and fibre proportions play a critical role in rumen and milk OBCFA content (Bas et al., 2003; Vlaeminck et al., 2004b; Cabrita et al., 2009) through their influence on the composition and development of the microbial population and, in particular, on numbers of bacteria of cellulolytic bacterial strains (Vlaeminck et al., 2004a). Odd chain fatty acids (OCFA) are formed through elongation of propionate or valerate whereas precursors of branched chain fatty acids (BCFA) are the branched chain amino acids valine, leucine and isoleucine, or the branched short chain carboxylic acids (BSCFA) isobutyric and isovaleric acid (Kaneda, 1991). A multiple linear regression based on OBCFA highlights the positive influence of ruminal iso C15:0, anteiso $\mathrm{C} 15: 0$ and anteiso $\mathrm{C} 17: 0$ on the molar proportion of acetate, while C15:0 was most important for the ruminal proportion of propionate (Vlaeminck et al., 2004b). Since the ruminal microbial population is influenced by a wide range of variables such as diet chemical composition, ruminal $\mathrm{pH}$, dietary $\mathrm{F} / \mathrm{C}$ ratio, ruminal $\mathrm{NH}_{3}$ concentration, these relationships have only been partially confirmed by others studies. Rigout et al. (2003) and Cabrita et al. (2007) found smaller responses in the C17:0 content of milk after ruminal infusion of propionic acid than in C15:0 content, while Dewhurst et al. (2007) found lower levels of $\mathrm{C} 15: 0$ and $\mathrm{C17}: 0$ in milk from cows fed with high $\mathrm{F} / \mathrm{C}$ ratios than from cows fed diets with low F/C ratios. OBCFA levels are negatively influenced by lipid supplements added to the diet (Bauchart et al., 1990a) and also by PSM (Cabiddu et al., 2009b, 2010), as a result of their inhibiting effect on the ruminal microbial population, directly by toxins or indirectly by reduction of nutrient substrate availability for the microbes. Overall, OBCFA levels in milk appears to be a potentially useful tool to evaluate rumen fermentation parameters, without ignoring effects of factors such as feed particle size and feed management, which can influence the rumen VFA profile (Dehority and Orpin, 1997; Loor et al., 2004). Indeed, except for C17:1 which is endogenously synthesized by the action of $\Delta^{9}$ desaturase (Fievez et al., 2003), C15:0 and C17:0 are partially de novo synthesized (Vlaeminck et al., 2006a; Cabrita et al., 2007). OBCFA have been confirmed to be extremely relevant as markers of ruminal microbial activity, especially when effects of incubation time of substrate or sample preparation methods of microbial colonization/contamination in vivo and in vitro need to be evaluated (Kim et al., 2005). Attempts to validate relationships between rumen OBCFA output and milk OBCFA are mixed compared with microbial markers such as diaminopimelic acid (DAPA) and purine bases (PB; Fievez et al., 2003). Vlaeminck et al. (2005) found that daily milk secretion of OBCFA was closely related to duodenal flow of DAPA and PB, with very low coefficients of variation (10.1\& and $10.0 \%$ for DAPA and PB, respectively). Dewhurst et al. (2007) also seem to indicate that milk OBCFA are not always related to duodenal flow of these FA, suggesting that correlating milk OBCFA level with rumen VFA may identify an interesting relationship between iso C14:0 and iso C15:0. These results also support the argument for there being a relationship between dietary NDF levels and iso C14:0 and iso C15:0 levels in ruminal microorganisms (Vlaeminck et al., 2006c). A relationship also 


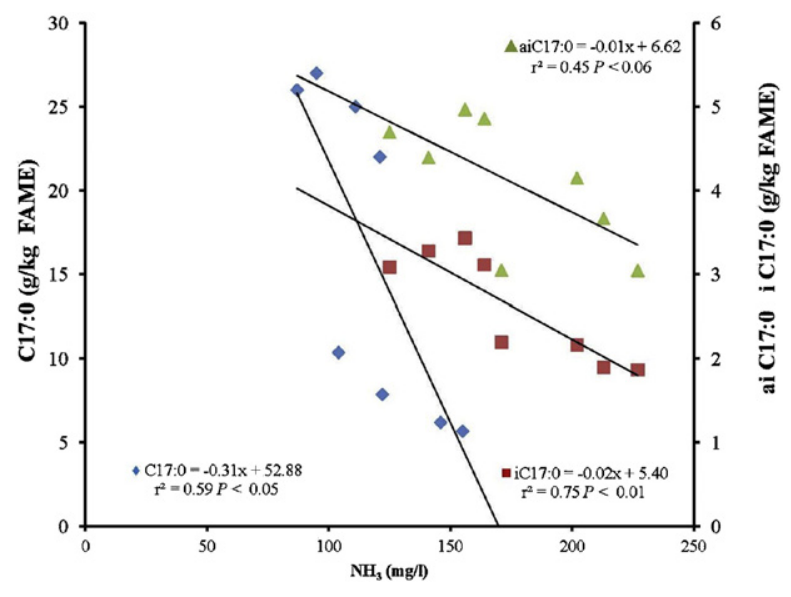

Fig. 15. Relationship between ruminal ammonia content and some OBCFA in the rumen. From Loor et al. (2002), Moorby et al. (2006), Lee et al. (2008b), and Dewhurst et al. (2007), adapted.

occurred between linear odd chain fatty acids (OCFA) and the proportion of propionate in the rumen because amylolytic bacteria contains high levels of OCFA (Vlaeminck et al., 2004b, 2006c), suggesting that it may be possible to predict rumen fermentation patterns from milk OBCFA, rather than from the chemical composition of the diet. In particular, the lower values of the root mean square prediction error between milk OBCFA and ruminal VFA (3.0\%, 9.0\% and 8.9\% for acetate, propionate and butyrate, respectively), during the validation of the prediction equation (Vlaeminck et al., 2006c), suggest that this new approach is correct.

New challenges in establishing the precise role of OBCFA include improving our understanding of the relationships between several cellulosolytic bacteria strains which contain high levels of odd-chain iso-fatty acids compared to amylolytic bacteria which are particularly rich in OCFA (Vlaeminck et al., 2006a). Vlaeminck et al. (2006a) found a decrease in iso C14:0 and iso $\mathrm{C} 15: 0$ and iso $\mathrm{C} 15: 0$, and an increase in the iso $\mathrm{C} 17: 0$ and anteiso $\mathrm{C} 17: 0$, proportion in milk from cows fed grass versus maize silage. However the results differed among cows, sheep and goats, perhaps because methylmalonyl-CoA synthesis uses the FA differently among species (Vlaeminck et al., 2006a). Understanding the mechanism of action of the ruminal microbial population remains a work in progress, although it is known that lipid supplements inhibit rumen bacteria in different ways, with Gram+ being more sensitive than Gram-, and that these effects change with the unsaturation levels and cis versus trans configuration of the FA. There are several opinions on the effects of supplementing ruminant diet with lipids. For example, a diet enriched in LA and LNA resulted in a reduction of OBCFA in milk, whereas a FO or marine algae supplement increased the total OBCFA content of milk (Vlaeminck et al., 2006a). Shingfield et al. (2008) showed that milk from cows fed diets supplemented with sunflower oils, with a high level of LA, linearly increased OBCFA levels (iso C15:0, C15:0 and anteiso C17:0) compared with milk from the unsupplemented group. The same results occurred in vitro, where bacterial synthesis of OBCFA increased with DHA supplement feeding level (Vlaeminck et al., 2008).

Some milk OBCFA levels are negatively correlated with dietary starch levels (iso C14:0, iso C15:0 and iso C16:0) while others (iso C15:0 and iso C14:0) are positively correlated. In a similar way, a negative relationship (Fig. 15) occurred between anteiso $\mathrm{C} 17: 0$ and ruminal $\mathrm{NH}_{3}$ as a potential marker of rumen protein degradability according to Vlaeminck et al. (2006a), who found a linear relationship between duodenal microbial protein flow and secretion of OBCFA in milk. However Doreau et al. (2007) did not confirm their findings, probably due to the difficulty of correlating OBCFA with duodenal microbial protein flow in individual cows, as recently reported by Gadeyne et al. (2011). Finally, iso C17:0 is strongly correlated with $\mathrm{BH}$ intermediates such us trans monene FA. OBCFA detection in milk could be a potential way to discriminate between grazing ruminants whose diets have different botanical composition, as reported by Lourenço et al. (2007) who found $40 \%$ higher levels of iso C17:0 in the rumen of lambs grazing natural pastures with high levels of plant diversity than in lambs grazing pasture rich in legumes or ryegrass. Unfortunately these results were not confirmed by Coppa et al. (2011) who found no differences in the iso C17:0 level in milk when they compared cows grazing pastures with different botanical compositions. The difficulty in describing the ruminal bacterial populations based on their OBCFA profile was confirmed by the higher levels of anteiso C15:0 in some strains of the B. fibrisolvens, the low content of this fatty acid in S. ruminantium and high content of iso C17:0 in some strains of Prevotella ruminicola (Vlaeminck et al., 2006b). Finally, as we shall see later, future evaluations of the protozoa/bacterial community ratio may be a useful way of improving the accuracy of predictions, and/or evaluation of rumen function, because the level of OBCFA in protozoa is consistent (110 versus $160 \mathrm{~g} / \mathrm{kg}$ of total FA in bacteria and protozoa, respectively), as reported by Or-Rashid et al. (2007). 


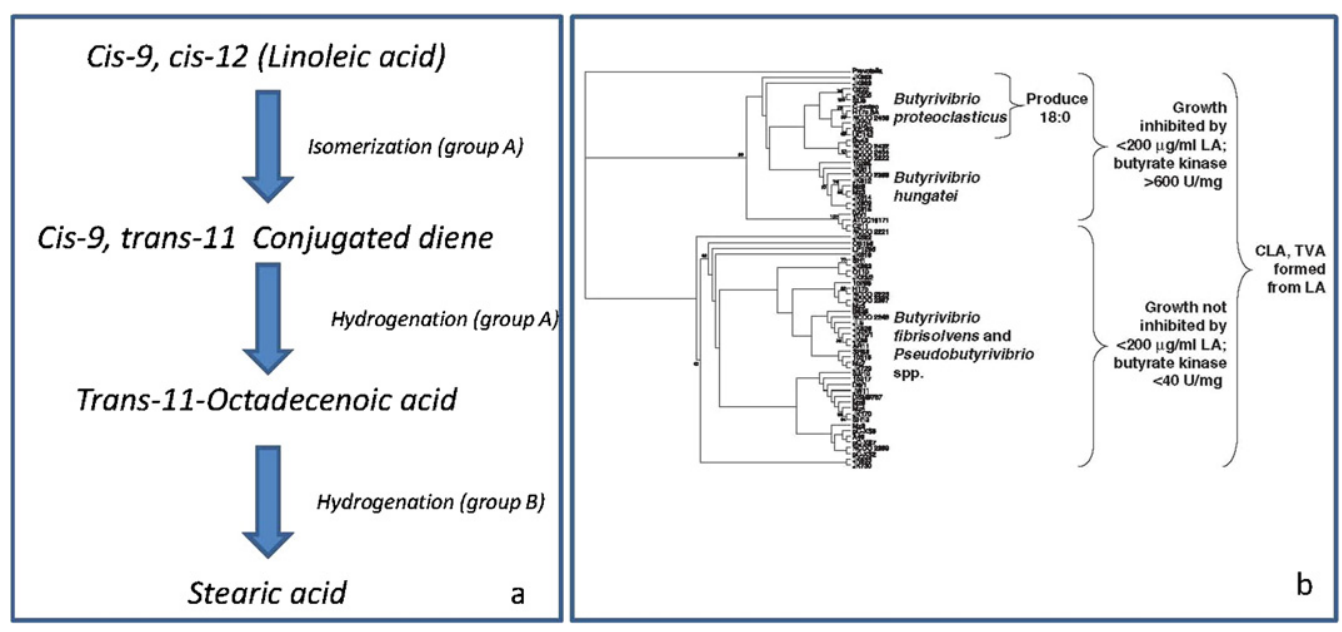

Fig. 16. Comparison of two approaches to classify ruminal bacterial on the basis of biohydrogenation power (a) or taxonomy (b). (a) is from Harfoot and Hazelwood (1988); (b) is from Lourenço et al. (2010).

\section{Future research needs}

\subsection{Interaction between pure culture and pure substrate}

Future research aimed at better understanding ruminal lipid metabolism should focus on the occurrence of biohydrogenated intermediates by studying lipid metabolism by pure bacterial strains growing on unique UFA substrates, quantifying impacts of protozoal isomerization mechanisms and their protective effects on $\mathrm{FA} \mathrm{BH}$, and evaluating effects of plant endogenous factors on LP and BH. In recent years the focus of research into lipid metabolisms has changed, with more attention being paid to identifying the metabolic pathways of substrates by means of culturing individual microbial strains. In this area, results from different groups propose different classification criteria of bacteria involved in the various PUFA biohydrogenation steps. In the case of Butyrivibrio spp., these criteria include the classical biohydrogenation steps (Fig. 16a), and the taxonomy (Fig. 16b) also based on toxic effect of linoleic acid. (Harfoot and Hazelwood, 1988; Lourenço et al., 2010). As reported in Section 3 of this paper, rumen bacteria involved in BH were classified either as group A (Hazlewood et al., 1979 as quoted by Kemp and Lander (1984) or group B (Kemp and Lander, 1984). Studying lipid metabolism with specific strains, associated with specific substrates, could be helpful because, as reported by McKain et al. (2010), when one compares various ruminal bacteria with their related biohydrogenated intermediates, then the reduction of CLA isomers $(9,11$ geometric isomers) occurs via different mechanisms compared with metabolism of other unsaturated FA (Fig. 17). These results explain why interpreting results of ruminal microbial ecology studies through BH products are more complex than originally thought. For example, B. proteoclasticum did not grow in the presence of CLA cis-9, trans-11 or CLA trans-10, cis-12, and their C18:0 production was also influenced by its growth phase (Wallace et al., 2006), suggesting that the fate of FA, both precursors and intermediates, is strongly influenced by the bacterial strains and their physiological stage (i.e., exponential versus stationary) of the microorganisms. The interaction between the protozoal and bacterial communities associated with specific substrates also appears interesting in relationship to their impact on $\mathrm{BH}$ intermediates. The ruminal microbial population (expressed as viable cells) consists of bacteria $\left(10^{10} / \mathrm{ml}\right.$ of ruminal liquid), protozoa $\left(10^{4}-10^{6} / \mathrm{ml}\right.$ of ruminal liquid) and fungi $\left(10^{3} / \mathrm{ml}\right.$ of ruminal liquid). Bacteria usually has the highest genetic diversity (Nam and Garnsworthy, 2007; Jenkins et al., 2008), and it is recognized that ruminal bacteria are mainly responsible for LP (Dawson et al., 1977; Jenkins et al., 2008; Lourenço et al., 2010) and BH (Nam and Garnsworthy, 2007). However, contrary to expectations, protozoa also influence the content of BH intermediate by isomerase (Devillard et al., 2006; Or-Rashid et al., 2011; Shen et al., 2011) as do fungi (Nam and Garnsworthy, 2007). Results of Or-Rashid et al. (2011) appear interesting in this context as their comparison of linoleic acid metabolism in bacteria, protozoa and their mixture showed that all metabolize linoleic acid to different CLA isomers and protozoa were incapable of biohydrogenating LA and, when tested in the bacterial/protozoal mixture, modulated BH of LA (Varadyova et al., 2008). The varying capacities of the microbial groups to metabolize LA reported in Figs. 17 and 18 show that bacterial/protozoal mixtures may have greater capability to biohydrogenate CLA cis-9, trans-11 to VA than bacteria alone, with a lower rate of ruminal biohydrogenation. This provides new insights into lipid metabolism through the newly identified intermediates trans-11, trans-13 CLA and cis-11, trans-13 CLA (Or-Rashid et al., 2011; Fig. 18). However the lack of SA production from C18:1 cis-12 and from C18:1 trans-12 remains to be examined. The ruminal biohydrogenate intermediate profile can be changed by modulating the hydrogenation/isomerization rate, as observed by Laverroux et al. (2011), who found that isomerization of VA appears to be very fast in the first $5 \mathrm{~h}$ of incubation with a $22.5 \%$ increase of the isomerization ratio when the rumen fluid came from cows fed a high $\mathrm{F} / \mathrm{C}$ diet. At present, it is not clear why this increased isomerization occurs at the expense of hydrogenation, although it is probably due to changes in the ruminal bacterial and 


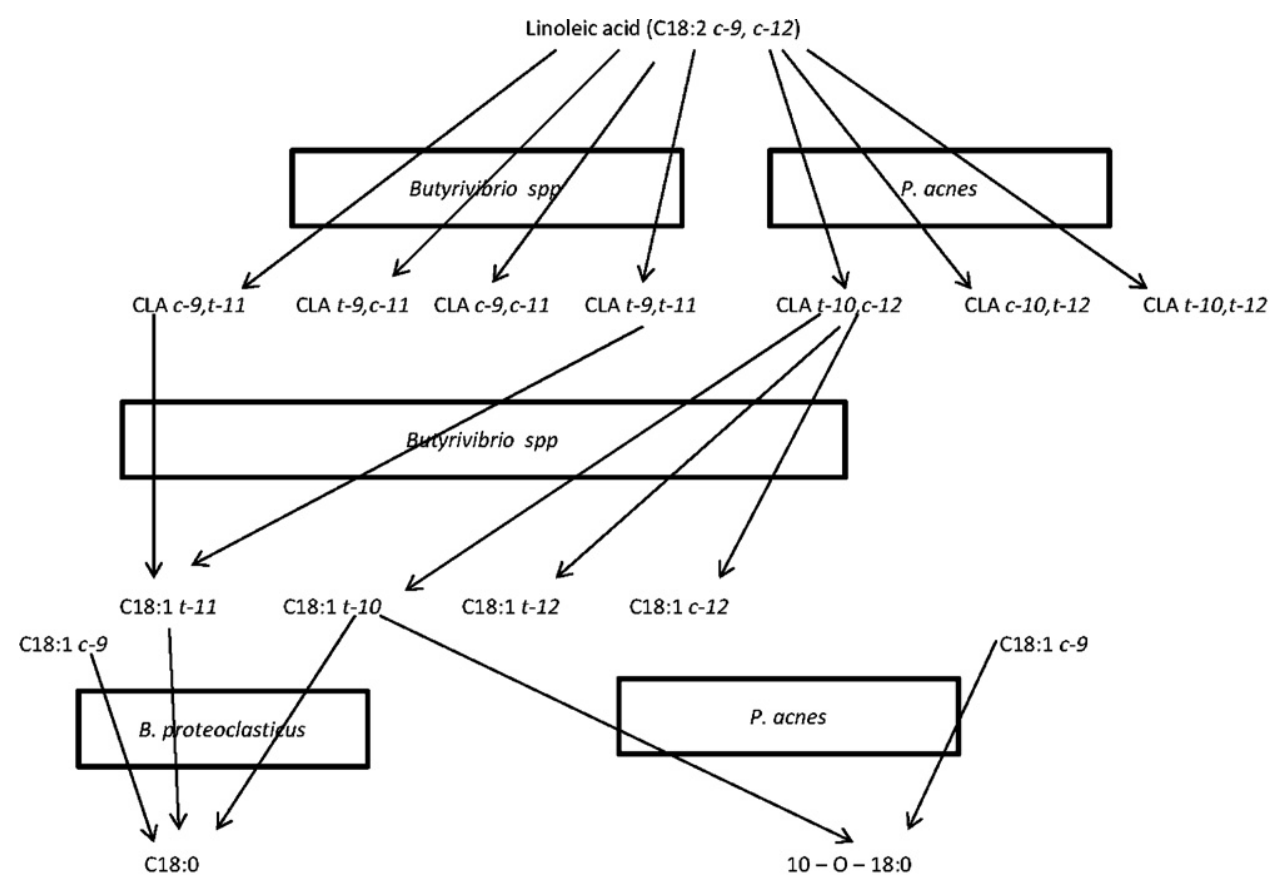

Fig. 17. Role of Butyrivibrio spp., Propionibacterium acnes and Butyrivibrio proteoclasticum on metabolism of the unsaturated fatty acids linoleic and oleic acids.

From McKain et al. (2010) and Wallace et al. (2006), modified.

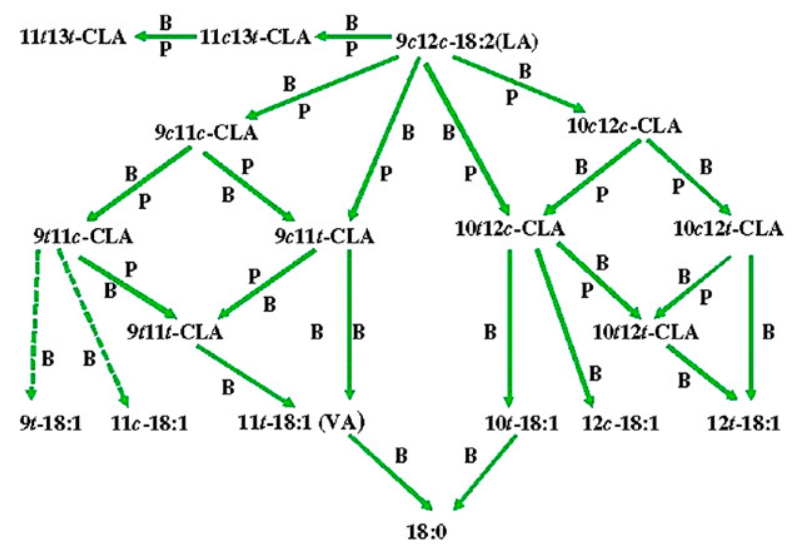

Fig. 18. Metabolic pathways for biosynthesis of CLA and related compounds from linoleic acid by rumen bacteria (B) and protozoa (P). Solid arrows are bacterial and protozoal activities leading to formation of isomers of CLA and C18:1, including C18:0, the minor dotted arrows are the bacterial activity leading to formation of the prospective compounds, and the major dotted arrows represent the bacterial activities.

From Or-Rashid et al. (2011), modified.

protozoal communities strains. All these changes are also found on the BH intermediates, and have impacts of different magnitudes on the ruminal bacteria and protozoa OBCFA.

\subsection{Interaction between PPO, PSM, endogenous lipolysis, and PUFA biohydrogenation}

Lipids in forage are less degraded than oils, as reported by Perrier et al. (1992). These results were confirmed by Wachira et al. (2000) who found a $15 \%$ lower linolenic BH ratio in sheep fed only green forage than in sheep also fed linseed-based supplements. This may be due to plants secondary metabolites, such as PPO and tannins (Vasta et al., 2009b; Van Ranst et al., 2011; Cabiddu et al., 2009b, 2010), but may also be due to protection of lipids from LP and BH by cellular structures, as reported by Doreau and Ferlay (1994). The literature suggests that BH levels are $820-850 \mathrm{~g} / \mathrm{kg}$ of LA and $920-970 \mathrm{~g} / \mathrm{kg}$ of LNA (Jalc et al., 2009a,b) in corn and grass silages. An interesting study completed by Lee et al. (2010) highlighted the influence of PPO on ruminal BH processes through its control of LP. Results from several studies showed that endogenous 


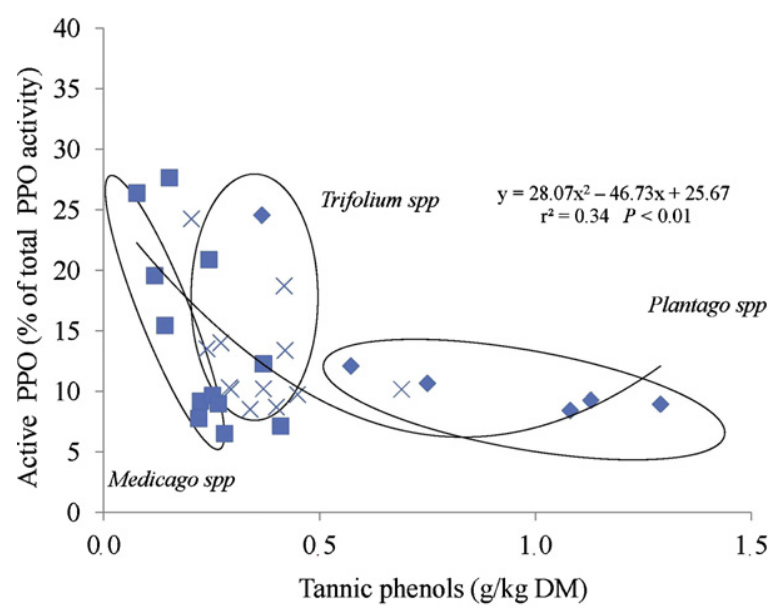

Fig. 19. Relationships between tannins contents and active PPO in Trifolium spp. (X) Plantago spp. ( ) Medicago spp. ( $\mathbf{\square})$. PPO activity was determined as $\Delta$ optical density/g fresh weight.

From Cabiddu et al. (2011), adapted.

$\mathrm{LP}$, after $24 \mathrm{~h}$ of incubation in a simulated rumen environment, ranged between $650 \mathrm{~g} / \mathrm{kg}$ of lipids for cocksfoot and $820 \mathrm{~g} / \mathrm{kg}$ for red clover (Lee et al., 2006, 2008a, 2010). These results do not agree with Bauchart et al. (1990b), who found that lipolysis was higher in cows fed lipid-supplemented diets than in those fed non supplemented diets. A strong interaction between ruminal $\mathrm{pH}$ and both microbial and endogenous lipases has been discovered: indeed the ruminal microbial population has an optimal pH of 6.0-6.7 (Tamminga and Doreau, 1991), while plant endogenous lypolitic systems need an optimum pH of 7-8, (Song et al., 2008). Since PUFA in forage are in the form of glycolipids, more studies on the endogenous lipolytic system appear required, which should focus on how galactolipase activity is influenced by PSM level, rather than PUFA, on microbial activity. As reported by Kaniuga (2008), studies on galactolipase activity are scant and related to effects of light and temperature, which reveal that it is possible to modulate this activity by genetically modifying plants. Only recently do some authors mention that galactolipase are capable of hydrolysing galactolipids and phospholipids, but not triglycerides (Matos and Pham-Thi, 2009), and that its activity is strongly influenced by forage species (Gemel and Kaniuga, 1987). Another endogenous factor which occurs in plants, such as Chrysanthemum coronarium, is coronaric acid $\left(\mathrm{C} 18: \mathrm{H}_{32} \mathrm{O}_{3}\right.$, an epoxy fatty acid) which can have inhibitory effects on rumen microorganism ( $-30 \%$ of ruminal $\mathrm{BH}$ respect to control) as reported by Wood et al. (2010). In addition Cabiddu et al. (2006) found that including C. coronarium, a daisy plant with a high level of LA, in the diet of grazing sheep increased milk CLA cis-9, trans- 11 by $60 \%$ and C18:1 trans- 11 by $60 \%$ through its inhibiting effect on ruminal microbial activity mediated by LA, and by increasing mammary gland $\Delta^{9}$ desaturase activity. It is recognized that $C$. coronarium also has PPO activity, with a probable synergistic or antagonistic effect on LP and BH. For this reason, it is necessary to understand the interactions of UFA, PPO, coronaric acid and others PSM and clarify the role of each component on the ruminal biohydrogenation pathways. Preliminary results from Cabiddu et al. (2011) showed that plant PPO activity could be affected by specific tannins with an interaction of forage species and plantphenological stage (Fig. 19).

\section{Conclusions}

The study of rumen FA metabolism is important to the understanding of factors which influence the types of FA in human food products derived from ruminants. Food products from ruminants are naturally rich in CLA, VA and CLNA, and the variation in the proportions of these FA in human foods is closely linked to the animals' diet.

The plant lipid fractions associated with these endogenous factors (i.e., PSM, PPO) affects rumen LP and BH. Although the critical role of bacteria in BH is well known, protozoa have also been shown to interact with FA metabolism to reduce BH and increase the extent of isomerization. This implies that there are unknown intermediate FA pathways.

A challenge in the future is to complete studies on plant lipid fractions in conjunction with PSM and PPO in order to discriminate between effects of plant lipids on FA biohydrogenate intermediates. This may become the basis for achieving more sustainable, less expansive and healthier ruminant derived human food.

\section{Acknowledgements}

This research was completed with the support of the Italian Animal Science and Production Association commission "Evaluation of in vitro techniques for the characterization of feeds and for the study of digestive processes of domestic animals". Special thanks must be given to the coordinator, Paolo Bani, without whose help it would not have been possible. The research also received financial support from PRIN Project 2007 - prot. 200778K3KJ - "Effects of tannins of some ruminant feeds on the rumen degradability of protein and fibre fractions, on the biohydrogenation of lipids and on the 
quality of milk and meat", from the Ministry of University and Research (MiUR). We would also like to thank the Regione Autonoma della Sardegna, which financed development of Sections 4-7 through the project "study of dietary strategies to improve the quality of dairy sheep products". Finally the authors are sincerely indebted to the anonymous referees whose detailed advice played a fundamental role in improving the manuscript.

\section{References}

Addis, M., Cabiddu, A., Pinna, G., Decandia, M., Piredda, G., Pirisi, A., Molle, G., 2005. Milk and cheese fatty acid composition of sheep fed different Mediterranean forages with particular reference to CLA cis-9, trans-11. J. Dairy Sci. 88, 3443-3454.

Akraim, F., Nicot, M.C., Juaneda, P., Enjalbert, F., 2007. Conjugated linolenic acid (CLnA), conjugated linoleic acid (CLA) and other biohydrogenation intermediates in plasma milk fat of cows fed raw or extruded linseed. Animal 6, 835-843.

Allakhverdiev, S.I., Kinoshita, M., Inaba, M., Suzuki, I., Murata, N., 2001. Unsaturated fatty acids in membrane lipids protect the photosynthetic machinery against salt-induced damage in synechococcus. Plant Phys. 125, 1842-1853.

Bas, P., Archimede, H., Rouzeau, A., Sauvant, D., 2003. Fatty acid composition of mixed-rumen bacteria: effect of concentration and type of forage. J. Dairy Sci. 86, 2940-2948.

Bauchart, D., Legay-Carmier, F., Doreau, M., Gaillard, B., 1990a. Lipid metabolism of liquid-associated and solid-adherent bacteria in rumen contents of dairy cows offered lipid-supplemented diets. Brit. J. Nutr. 63, 563-578.

Bauchart, D., Legay-Carmier, F., Doreau, M., 1990b. Ruminal hydrolysis of dietary triglycerides in dairy cows fed lipid-supplemented diets. Reprod. Nutr. Dev. S2, 187S.

Bernard, L., Bonnet, M., Leroux, C., Shingfield, K.J., Chilliard, Y., 2009. Effect of sunflower-seed oil and linseed oil on tissue lipid metabolism, gene expression, and milk fatty acid secretion in alpine goats fed maize silage-based diets. J. Dairy Sci. 92, 6083-6094.

Bessa, R.J.B., Santos-Silva, J., Ribeiro, J.M.R., Portugal, A.V., 2000. Reticulo-rumen biohydrogenation and the enrichment of ruminant edible products with linoleic acid conjugated isomers. Livest. Prod. Sci. 63, 201-211.

Bessa, R.J.B., Maia, M.R.G., Jerónimo, E., Belo, A.T., Cabrita, A.R.J., Dewhurst, R.J., Fonseca, A.J.M., 2009. Using microbial fatty acids to improve understanding of the contribution of solid associated bacteria to microbial mass in the rumen. Anim. Feed Sci. Technol. 150, 197-206.

Bromley, P.E., Li, Y.O., Murphy, S.M., Sumner, C.M., Lync, D.V., 2003. Complex sphingolipid synthesis in plants: characterization of inositolphosphorylceramide synthase activity in bean microsomes. Arch. Biochem. Biophys. 417, 219-226.

Buccioni, A., Antongiovanni, M., Petacchi, F., Mele, M., Serra, A., Secchiari, P., Benvenuti, D., 2006. Effect of dietary fat quality on C18:1 fatty acids and conjugated linoleic acid production: an in vitro rumen fermentation study. Anim. Feed Sci. Technol. 127, 268-282.

Buccioni, A., Antongiovanni, M., Petacchi, F., Mele, M., Serra, A., Secchiari, P., Minieri, S., 2008. Effect of dried or green herbage on vaccenic acid and conjugated linoleic acid production during in vitro rumen fermentation. Anim. Feed Sci. Technol. 140, 207-213.

Buccioni, A., Antongiovanni, M., Minieri, M., Rapaccini, R., Pratesi, V., Mele, M., 2009. Effect of three species of herbage (Medicago sativa, Lolium multiflorum, Avena sativa) in in vitro ruminal production of conjugated linoleic and vaccenic acids. Ital. J. Anim. Sci. 8, 231-244.

Cabiddu, A., Addis, M., Spada, S., Sitzia, M., Molle, G., Piredda, G., 2004. The effect of different legume-based pastures on the fatty acid composition of sheep milk with focus on CLA. In: Lüscher, A., Jeangros, B., Kessler, W., Huguenin, O., Lobsiger, M., Millar, N., Suter, D. (Eds.), Land Use Systems in Grassland Dominated Regions. ETH Zentrum Zurich, Switzerland, pp. 1133-1135.

Cabiddu, A., Decandia, M., Addis, M., Piredda, G., Pirisi, A., Molle, G., 2005. Managing Mediterranean pastures in order to enhance the level of beneficial fatty acids in sheep milk. Small Rum. Res. 59, 169-180.

Cabiddu, A., Addis, M., Pinna, G., Spada, S., Fiori, M., Sitzia, M., Pirisi, A., Piredda, G., Molle, G., 2006. The inclusion of a daisy plant (Chrysanthemum coronarium) in dairy sheep diet. 1: effect on milk and cheese fatty acid composition with particular reference to C18:2 cis-9, trans-11. Livest. Sci. 101, 57-67.

Cabiddu, A., Addis, M., Spada, S., Acciaro, M., Sitzia, M., Decandia, M., Molle, G., 2009a. Effect of different supply and different source of polyunsaturated fatty acid on milk fat synthesis of grazing dairy sheep. In: Chilliard, Y., Glasser, F., Faulconnier, Y., Boquier, F., Veissier, I., Doreau, M. (Eds.), Ruminant Physiology. Wageningen Academic Publishers Wageningen, Netherlands, pp. 474-475.

Cabiddu, A., Molle, G., Decandia, M., Spada, S., Fiori, M., Piredda, G., Addis, M., 2009b. Responses to condensed tannins of flowering sulla (Hedysarum coronarium L.) grazed by dairy sheep. Part 2: effects on milk fatty acid profile. Livest. Sci. 123, 230-240.

Cabiddu, A., Decandia, M., Salis, L., Scanu, G., Fiori, M., Addis, M., Sitzia, M., Molle, G., 2009c. Effect of species, cultivar and phonological stage of different forage legumes on herbage fatty acid composition. Ital. J. Anim. Sci. 8 (S2), 277-279.

Cabiddu, A., Salis, L., Tweed, J.K.S., Molle, G., Decandia, M., Lee, M.R.F., 2010. The influence of plant polyphenols on lipolysis and biohydrogenation in dried forages at different phenological stages: in vitro study. J. Sci. Food Agric. 90, 829-835.

Cabiddu, A., Lee, M.R.F., Decandia, M., Molle, G., Salis, L., Vargiu, M., Winters, A.L., 2011. Characterization of polyphenol oxidase activity in different forage ecotypes with different phenolic substrates. Adv. Anim. Biosci. 2, 543.

Cabrita, A.R.J., Bessa, R.J.B., Alves, S.P., Dewhurst, R.J., Fonseca, A.J.M., 2007. Effects of dietary protein and starch on intake, milk production, and milk fatty acid profiles of dairy cows fed corn silage-based diets. J. Dairy Sci. 90,1429-1439.

Cabrita, A.R.J., Vale, J.M.P., Bessa, R.J.B., Dewhurst, R.J., Fonseca, A.J.M., 2009. Effects of dietary starch source and buffers on milk responses and rumen fatty acid biohydrogenation in dairy cows fed maize silage-based diets. Anim. Feed Sci. Technol. 152, 267-277.

Carlsen, C.K., Fomsgaard, I.S., 2008. Biologically active secondary metabolites in white clover (Trifolium repens L.) -a review focusing on contents in the plant, plant-pest interactions and transformation. Chemoecology 18, 129-170.

Carter, R.H.E., Mccluer, H., Slifer, E.D., 1956. Lipids of wheat flour. I. Characterization of galactosylglycerol components. J. Biol. Chem. Soc. 268, 17794-17802.

Carter, E., Strobach, D.R., Hawthorne,J.N., 1969. Biochemistry of the sphingolipids. XVIII. Complete structure of tetrasaccharide phytoglycolipid. Biochemistry $8,383-388$.

Chilliard, Y., Ferlay, A., Doreau, M., 2001. Effect of different types of forages, animal fat or marine oils in cow's diet on milk fat secretion and composition, especially conjugated linoleic acid (CLA) and polyunsaturated fatty acids. Livest. Prod. Sci. 70, 31-48.

Chilliard, Y., Ferlay, A., Rouel, J., Lamberet, G., 2003. A review of nutritional and physiological factors affecting goat milk lipid synthesis and lipolysis. J. Dairy Sci. 86, 1751-1770.

Chilliard, Y., Glasser, F., Ferlay, A., Bernard, L., Rouel, J., Doreau, M., 2007. Diet, rumen biohydrogenation and nutritional quality of cow and goat milk fat. Eur. J. Lipid Sci. Technol. 109, 828-855.

Chow, T.T., Fievez, V., Moloney, A.P., Raes, K., Demeyer, D., De Smet, S., 2004. Effect of fish oil on in vitro rumen lipolysis, apparent biohydrogenation of linoleic and linolenic acid and accumulation of biohydrogenation intermediates. Anim. Feed Sci. Technol. 117, 1-12.

Coppa, M., Verdier-Metz, I., Ferlay, A., Pradel, P., Didienne, R., Farruggia, A., Montel, M.C., Martin, B., 2011. Effect of different grazing systems on upland pastures compared with hay diet on cheese sensory properties evaluated at different ripening times. Int. Dairy J. 21, 815-822.

Crombie, M.W., 1958. Fatty acids in chloroplast and leaves. J. Exp. Bot. 9, 254-261.

Czerkawski, J.W., 1984. Microbial fermentation in the rumen. Proc. Nutr. Soc. 43, 101-118.

Czerkawski, J.W., 1986. Degradation of solid feeds in the rumen: spatial distribution of microbial activity and its consequences. In: Milligan, L.P., Grovum, W.L., Dobson, A. (Eds.), Control of Digestion and Metabolism in Ruminants. Prentice Hall, Englewood Cliffs, NJ, USA, pp. 158-172.

Dawson, R.M., Hemington, N., Grime, D., Lander, D., Kemp, P., 1974. Lypolysis and hydrogenation of galactolipids and the accumulation of phytanic acid in the rumen. J. Biochem. 144, 169-171. 
Dawson, R.M.C., Hemington, N., Hazlewood, G.P., 1977. On the role of higher plant and microbial lipases in the ruminal hydrolysis of grass lipids. Brit. J. Nutr. 38, 225-232.

Dehority, B.A., Orpin, C.G., 1997. Development of, and natural fluctuations in, rumen microbial populations. In: Hobson, P.N., Stewart, C.S. (Eds.), The Rumen Microbial Ecosystem. Chapman \& Hall, London, UK, pp. 196-245.

Dehority, B.A., 2003. Rumen Microbiology. Nottingham University Press, Nottingham, UK, 372 pp.

Destaillats, F., Trottier, J.P., Galvez, J.M.G., Angers, P., 2005. Analysis of $\alpha$-linolenic acid biohydrogenation intermediates in milk fat with emphasis on conjugated linolenic acid. J. Dairy Sci. 88, 3231-3239.

Devillard, E., McIntosh, F.M., Castet, R.J., Wallace, J., Newbold, C.J., 2004. Conjugated linoleic acid composition of rumen bacterial and protozoal populations. Reprod. Nutr. Dev. 44 (Suppl. 1), 60.

Devillard, E., McIntosh, F.M., Newbold, C.J., Wallace, R.J., 2006. Rumen ciliate protozoan contain high concentration of conjugated linoleic acids and vaccenic acid, yet do not hydrogenate linoleic acid or desaturate stearic acid. Brit. J. Nutr. 96, 697-704.

Dewhurst, R.J., Scollan, N.D., Youell, S.J., Tweed, J.K.S., Humphreys, M.O., 2001. Influence of species, cutting date and cutting interval on the fatty acid composition of grasses. Grass Forage Sci. 56, 68-74.

Dewhurst, R.J., Evans, R.T., Scollan, N.D., Moorby, J.M., Merry, R.J., Wilkins, R.J., 2003. Comparison of grass and legume silages for milk production. 2. In vivo and in sacco evaluations of rumen function. J. Dairy Sci. 86, 2612-2621.

Dewhurst, R.J., Lee, M.R.F., 2004. Alternative strategies for manipulating milk fat in dairy cows. In: Garnsworthy, P.C., Wiseman, J. (Eds.), Recent Advances in Animal Nutrition. Nottingham University Press, Nottingham, UK, pp. 255-275.

Dewhurst, R.J., Moorby, J.M., Vlaeminck, B., Fievez, V., 2007. Apparent recovery of duodenal odd- and branched-chain fatty acids in milk of dairy cows. J. Dairy Sci. 90, 1775-1780.

Dhiman, T.R., Anand, G.R., Satter, L.D., Pariza, M.W., 1999. Conjugated linoleic acid content of milk from cows fed different diets. J. Dairy Sci. 82, 2146-2156.

Donovan, D.C., Schingoethe, D.J., Baer, R.J., Ryali, J., Hippen, A.R., Franklin, S.T., 2000. Influence of dietary fish oil on conjugated linoleic acid and other fatty acids in milk fat from lactating dairy cows. J. Dairy Sci. 83, 2620-2628.

Doreau, M., Ferlay, A., 1994. Digestion and utilization of fatty acids by ruminants. Anim. Feed Sci. Technol. 45, $379-396$.

Doreau, M., Rearte, D., Portelli, J., Peyraud, J.L., 2007. Fatty acid ruminal metabolism and digestibility in cows fed perennial ryegrass. Eur. J. Lip. Sci. Technol. 109, 790-798.

Dörman, P., Benning, C., 2002. Galactolipids rule in seed plants. Trends in Plant Sci. 7, 112-118.

Dörman, P., 2005. Membrane lipids. In: Denis, J. (Ed.), Plant Lipids. Murphy Blackwell Publishing/CRC Press LLC, New York, NY, USA, pp. $123-161$.

Elgersma, A., Ellen, G., Van der Horst, H., Muuse, B.G., Boer, H., Tamminga, S., 2003. Comparison of the fatty acid composition of fresh and ensiled perennial ryegrass (Lolium perenne L.), affected by cultivar and regrowth interval. Anim. Feed Sci. Technol. 108, 191-205.

Fay, J.P., Jakober, K.D., Cheng, K.J., Costerton, J.W., 1990. Esterase activity of pure cultures of rumen bacteria as expressed by the hydrolysis of pnitrophenylpalmitate. Can. J. Microbiol. 36, 585-589.

Faruque, A.J.M.O., Jarvis, B.D.W., Hawke, J.C., 1974. Studies on rumen metabolism: VII characteristics of lipases in rumen content and in rumen bacteria. J. Sci. Food Agric. 25, 439-449.

Fievez, V., Vlaeminck, B., Dhanoa, M.S., Dewhurst, R.J., 2003. Use of principal component analysis to investigate the origin of heptadecanoic and conjugated linoleic acids in milk. J. Dairy Sci. 86, 4047-4053.

Gadeyne, F., Aschemann, M., Ariko, T., De Campeneere, S., Vlaeminck, B., Lebzien, P., Fievez, V., 2011. Milk odd-and branched-chain fatty acids: biomarkers to optimize microbial metabolism by ruminant? Adv. Anim. Biosci. 2, 357.

Garton, G.A., 1960. Fatty acid composition of the lipids of pasture grasses. Nature 4736, 511-512.

Gemel, J., Kaniuga, Z., 1987. Comparison of galactolipase activity and free fatty acid levels in chloroplasts of chill-sensitive and chill-resistant plants. Eur. J. Biochem. 166, 229-233.

Gerson, T., John, A., King, A.S.D., 1986. Effects of feeding ryegrass of varying maturity on the metabolism and composition of lipids in the rumen of sheep. J. Agric. Sci. 106, 445-448.

Gerson, T., King, A.S.D., Kelly, K.E., Kelly, W.J., 1988. Influence of particle size and surface area on in vitro rates of gas production, lipolysis of triacylglycerols and hydrogenation of linoleic acid by sheep rumen digesta or Ruminococcus flavefaciens. J. Agric. Sci. 110, 31-37.

Gounaris, K., Barber, J., Harwood, J.L., 1986. The thylakoid membranes of higher plant chloroplast. J. Biochem. 237, 313-326.

Griinari, J.M., Chouinard, P.Y., Bauman, D.E.,1997. Trans fatty acid hypothesis of milk fat depression revisited. In: Proc. Cornell Nutrition Conf. for Feed Manufactures. Cornell University, Ithaca, NY, USA, pp. 208-216.

Griinari, J.M., Dwyer, D.A., McGuire, M.A., Bauman, D.E., Palmquist, D., Nurmela, K.V.V., 1998. Trans octadecanoic acids and milk fat depression in lactating dairy cows. J. Dairy Sci. 81, 1251-1261.

Griinari, J.M., Bauman, D.E., 1999. Biosynthesis of conjugated linoleic acid and its incorporation into meat and milk in ruminants. In: Yurawecz, M.P., Mossoba, M.M., Kramer, J.K.G., Pariza, M.W., Nelson, G.J. (Eds.), Advances in Conjugated Linoleic Acid Research, vol. 1. AOCS Press, Champaign, IL, USA, pp. $180-200$.

Griinari, J.M., Cori, B.A., Lacy, S.H., Chouinard, P.Y., Nurmela, K.V.V., Bauman, D.E., 2000. Conjugated linoleic acid is synthesized endogenously in lactating dairy cows by $\Delta^{9}$-desaturase. J. Nutr. 130, 2285-2291.

Griinari, J.M., Bauman, D.E., 2006. Milk fat depression: concepts, mechanism and management application. In: Sejrsen, K., Hvelplund, T., Nielsen, M.O. (Eds.), Ruminant Physiology Digestion, Metabolism and Impact Nutrition on Gene Expression, Immunology and Stress. Wageningen Academic Publishers, Amsterdam, Netherlands, pp. 389-417.

Hannun, Y.A., Luberto, C., Argraves, K.M., 2001. Enzymes of sphingolipid metabolism: from modular to integrative signalling. Biochemistry 40, $4893-4903$.

Harfoot, C.G., Noble, R.C., Moore, J.H., 1973. Factors influencing the extent of biohydrogenation of linoleic acid by rumen microorganism in vitro. J. Food Agric. 24, 961.

Harfoot, C.G., Noble, R.C., Moore, J.H., 1975. The role of plant particles, bacteria and cell-free supernatant fractions of rumen contents in the hydrolysis of trilinolein and subsequent hydrogenation of linoleic acid. Antonie van Leeuwenhoek 41, 533-542.

Harfoot, C.G., 1978. Lipid metabolism in the rumen. Prog. Lipid Res. 17, 21-54.

Harfoot, C.G., Hazelwood, G.P., 1988. Lipid metabolism in the rumen. In: Hobson, P.N. (Ed.), The Rumen Microbial Ecosystem. Elsevier Applied Science, Amsterdam, Netherlands, pp. 285-322.

Harvatine, K.J., Allen, M.S., 2006. Fat supplements affect fractional rates of ruminal fatty acid biohydrogenation and passage in dairy cows. J. Nutr. 136, $677-685$.

Hawke, J.C., 1973. Lipids. In: Butler, G.W., Bailey, R.W. (Eds.), Chemistry and Biochemistry of Herbage, vol. 1. Academic Press, London, UK, pp. 212-263.

Hazlewood, G.P., Reynolds, M.J., Dawson, R.M.C., Gunstonef, D., 1979. An automatic colorimeter and its use in evaluating the growth response of an anaerobic general fatty acid auxotroph to cis- and trans-octadecenoic acids. J. Appl. Bacteriol. 47, 321-325.

Heinz, E., Siefermann-Harms, D., 1981. Are galactolipids integral components of the chlorophyll protein complex in spinach thylakoids? FEBS Lett. 124, $105-111$.

Henderson, C., 1971. A study of the lipase produced by Anaerovibrio lipolytica, a rumen bacterium. J. Gen. Microbiol. 65, 81-89.

Hsieh, T.C.Y., Kaul, K., Laine, R.A., Robert, L., Lester, R.L., 1978. Structure of a major glycophosphoceramide from tobacco leaves, PSL-1:2-deoxy-2-acetamidoD-glucopyranosyl $(\alpha 1 \rightarrow 4)$-D-glucuronopyranosyl $(\alpha 1 \rightarrow 2)$ myoinositol-1-O-phosphoceramide. Biochemistry 17, 3575-3581.

Hudson, B.J.F., Warwick, M.J., 1977. Lipid stabilization in leaf protein concentrates from ryegrass. J. Sci. Food Agric. $28,259-264$.

Hudson, J.A., MacKenzie, C.A., Joblin, K.N., 1995. Conversion of oleic acid to 10-hydroxystearic acid by two species of ruminal bacteria. Appl. Microbiol. Biotechnol. 44, 1-6. 
Hudson, J.A., Cai, Y., Corner, R.J., Morvan, B., Joblin, K.N., 2000. Identification and enumeration of oleic acid and linoleic acid hydrating bacteria in the rumen of sheep and cows. J. Appl. Microbiol. 88, 286-292.

Hughes, P.E., Hunter, W.J., Tove, S.B., 1982. Biohydrogenation of unsaturated fatty acids. Purification and properties of cis-9, trans-11-octadecadienoate reductase. J. Biol. Chem. 257, 3643-3649.

Huws, S.A., Lee, M.R.F., Muetzel, S.M., Scott, M.B., Wallace, R.J., Scollan, N.D., 2010. Forage type and fish oil cause shifts in rumen bacterial diversity. FEMS Microbiol. Ecol. 73, 396-407.

Huws, S.A., Kim, E.U., Lee, M.R.F., Scott, M.B., Tweed, J.K.S., Pinloche, E., Wallace, R.J., Scollan, N.D., 2011. As yet uncultured bacteria phylogenetically classified as Prevotella, Lachnospiraceae incertae sedis and unclassified Bacteroidales, Clostridiales and Ruminococcaceae may play a predominant role in ruminal biohydrogenation. Environ. Microbiol. 13, 1500-1512.

Jalc, D., Lauková, A., Váradyová, Z., Homolka, P., Koukolová, V., 2009a. Effect of inoculated grass silages on rumen fermentation and lipid metabolism in an artificial rumen (RUSITEC). Anim. Feed Sci. Technol. 151, 55-64.

Jalc, D., Varadyova, Z., Laukova, A., 2009b. Effect of inoculated corn silage enriched with sunflower oil on rumen fermentation and lipid metabolism in an artificial rumen (RUSITEC). J. Sci. Food Agric. 90, 78-84.

Jarrige, R., Grenet, E., Demarquilly, C., Besle, J.M., 1995. The components of fodder plants. In: Jarrige, R., Ruckebusch, Y., Demarquilly, C., Farcen, M.H., Journet, M. (Eds.), Nutrition des ruminants domestiques. Ingestion et digestion. INRA éditions, Paris, France, pp. $25-81$.

Jenkins, T.C., 1993. Lipid metabolism in the rumen. J. Dairy Sci. 76, 3851-3863.

Jenkins, T.C., AbuGhazaleh, A.A., Freeman, S., Thies, E.J., 2006. The production of 10-hydroxystearic acid and 10-ketostearic acids is an alternate route of oleic acid transformation by the ruminal microbiota in cattle. J. Nutr. 136, 926-931.

Jenkins, T.C., Wallace, R.J., Moate, P.J., Mosley, E.E., 2008. Board-invited review: recent advances in biohydrogenation of unsaturated fatty acids within the rumen microbial ecosystem. J. Anim. Sci. 86, 397-412.

Jones, B.A., Muck, R.E., Hatfield, R.D., 1995. Red clover extracts inhibit legume proteolysis. J. Sci. Food Agric. 67, 329-333.

Jouhet, J., Marechal, E., Block, M.A., 2007. Glycerolipid transfer for the building of membranes in plant cells. Prog. Lipid Res. 46, 37-55.

Kadegowda, A.K.G., Piperova, L.S., Erdman, R.A., 2008. Principal component and multivariate analysis of milk long-chain fatty acid composition during diet-induced milk fat depression. J. Dairy Sci. 91, 749-759.

Kalscheur, K.F., Teter, B.B., Piperova, L.S., Erdman, R.A., 1997. Effect of dietary forage concentration and buffer addition on duodenal flow of trans-C18:1 fatty acids and milk fat production in dairy cows. J. Dairy Sci. 80, 2104-2114.

Kaneda, T., 1991. Iso- and anteiso-fatty acids in bacteria: biosynthesis, function, and taxonomic significance. Microbiol. Rev. $55,288-302$.

Kaniuga, Z., 2008. Chilling response of plants: importance of galactolipase, free fatty acids and free radicals. Plant Biol. 10, $171-184$.

Kemp, P., Lander, D.J., 1984. Hydrogenation in vitro of $\alpha$-linolenic acid to stearic acid by mixed culture of pure strains of rumen bacteria. J. Gen. Microbiol. $130,527-533$

Kepler, C.R., Hirons, K.I., McNeill, P.H., Tove, S.B., 1966. Intermediates and products of biohydrogenation of linoleic acid by Butyrivibrio fibrisolvens. J. Biol. Chem. 241, 1350-1354.

Kepler, C.R., Tove, S.B., 1967. Biohydrogenation of unsaturated fatty acids: III. Purification and properties of a linoleate $\Delta 12$-cis, $\Delta 11$-trans-isomerase from Butyrivibrio fibrisolvens. J. Biol. Chem. 242, 5686-5692.

Kepler, C.R., Tucker, W.P., Tove, S.B., 1970 . Biohydrogenation of unsaturated fatty acids. IV. Substrate specificity and inhibition of linoleate $\Delta 12$-cis, $\Delta 11$-trans isomerase from Butyrivibrio fibrisolvens. J. Biol. Chem. 245, 3612-3620.

Kim, E.J., Sanderson, R., Dhanoa, M.S., Dewhurst, R.J., 2005. Fatty acid profiles associated with microbial colonization of freshly ingested grass and rumen biohydrogenation. J. Dairy Sci. 88, 3220-3230.

Kim, E.J., Huws, S.A., Lee, M.R.F., Wood, J.D., Muetzel, S.M., Wallace, R.J., Scollan, N.D., 2008. Fish oil increases the duodenal flow of long chain polyunsaturated fatty acids and trans-11 18:1 and decreases 18:0 in steers via changes in the rumen bacterial community. J. Nutr. 138, 889-896.

Kramer, J.K.G., Sehat, N., Fritsche, J., Mossoba, M.M., Eulitz, K., Yurawecz, M.P., Ku, Y., 1999. Separation of conjugated linoleic acid isomers. In: Yurawecz, M.P., Mossoba, M.M., Kramer, J.K.G., Pariza, M.W., Nelson, G.J. (Eds.), Advances in Conjugated Linoleic Acid Research, vol. 1. AOCS Press, Champaign, IL, USA, pp. 81-109.

Kramer, J.K.G., Cruz-Hernandez, C., Deng, Z., Zhou, J., Jahreis, G., Dugan, M.E.R., 2004. Analysis of conjugated linoleic acid and trans 18:1 isomers in synthetic and animal products. Am. J. Clin. Nutr. 79, 11375-11445.

Krebsky, E.O., Geuns, J.M.C., De Proft, M., 1996. Fatty acids in polar lipids from etiolated Cichorium intybus. Phytochemistry 43, 747-751.

Latham, M.J., Storry, J.E., Sharpe, M.E., 1972. Effect of low roughage diets on the microflora and lipid metabolism in the rumen. Appl. Microbiol. 24, 871-877.

Laverroux, S., Glasser, F., Gillet, M., Joly, C., Doreau, M., 2011. Isomerization of vaccenic acid to cis and trans C18:1 isomers during biohydrogenation by rumen microbes. Lipids 46, 843-850.

Lee, M.R.F., Martinez, E.M., Scollan, N.D., 2003. Plant enzyme mediated lipolysis of Lolium perenne and Trifolium pratense in an in vitro simulated rumen environment. Aspects Appl. Biol. 70, 115-120.

Lee, M.R.F., Winters, A.L., Scollan, N.D., Dewhurst, R.J., Theodorou, M.K., Minchin, F.R., 2004. Plant-mediated lipolysis and proteolysis in red clover with different polyphenol oxidase activities. J. Sci. Food Agric. 84, 1639-1645.

Lee, M.R.F., Colmenero, J., de, J.O., Winters, A.L., Scollan, N.D., Minchin, F.R., 2006. Polyphenol oxidase activity in grass and its effect on plant-mediated lipolysis and proteolysis of Dactylis glomerata (cocksfoot) in a simulated rumen environment. J. Sci. Food Agric. 86, 1503-1511.

Lee, M.R.F., Huws, S.A., Scollan, N.D., Dewhurst, R.J., 2007a. Effects of fatty acid oxidation products (green odor) on rumen bacterial populations and lipid metabolism in vitro. J. Dairy Sci. 90, 3874-3882.

Lee, M.R.F., Parfitt, L.J., Scollan, N.D., Minchin, F.R., 2007b. Lipolysis in red clover with different polyphenol oxidase activities in the presence and absence of rumen fluid. J. Sci. Food Agric. 87, 1308-1314.

Lee, M.R.F., Scott, M.B., Tweed, J.K.S., Minchin, F.R., Davies, D.R., 2008a. The effect of polyphenol oxidase on lipolysis and proteolysis of red clover silage with and without a silage inoculant (Lactobacillus plantarum L54). Anim. Feed Sci. Technol. 144, 125-136.

Lee, M.R.F., Shingfield, K.J., Tweed, J.K.S., Toivonen, V., Huws, S.A., Scollan, N.D., 2008b. Effect of fish oil on ruminal biohydrogenation of C18 unsaturated fatty acids in steers fed grass or red clover silages. Animal 2, 1859-1869.

Lee, M.R.F., Theobald, V.J., Tweed, J.K.S., Winters, A.L., Scollan, N.D., 2009a. Effect of feeding fresh or conditioned red clover on milk fatty acids and nitrogen utilization in lactating dairy cows. J. Dairy Sci. 92, 1136-1147.

Lee, M.R.F., Tweed, J.K.S., Minchin, F.R.L., Winters, A.L., 2009b. Red clover polyphenol oxidase: activation, activity and efficacy under grazing. Anim. Feed Sci. Technol. 149, 250-264.

Lee, M.R.F., Tweed, J.K.S., Cookson, A., Sullivan, M.L., 2010. Immunogold labelling to localize polyphenol oxidase (PPO) during wilting of red clover leaftissue and the effect of removing cellular matrices on PPO protection of glycerol-based lipid in the rumen. J. Sci. Food Agric. 90, 503-510.

Lee, M.R.F., Cabiddu, A., Hou, F., Niderkorn, V., Kim, E.J., Scollan, N.D., 2011. In vitro rumen simulated (RUSITEC) metabolism of freshly cut or wilted grasses with contrasting polyphenol oxidase activities. Grass Forage Sci. 66, 196-205.

Legay-Carmier, F., Bauchart, D., 1989. Distribution of bacteria in the rumen contents of dairy cows given a diet supplemented with soya-bean oil. Brit. J. Nutr. 61, 725-740.

Lehninger, A.L., 1979. Biochimica, 2th ed. Zanichelli, Bologna, Italy, 998 pp.

Liavonchanka, A., Hornung, E., Feussner, I., Rudolph, M.G., 2006. Structure and mechanism of the Propionibacterium acnes polyunsaturated fatty acid isomerase. Proc. Natl. Acad. Sci. U.S.A. 103, 2576-2581.

Lock, A.L., Tyburczy, C., Dwyer, D.A., Harvatine, K.J., Destaillats, F., Mouloungui, Z., Candy, L., Bauman, D.E., 2007. Trans-10 octadecanoic acid does not reduce milk fat synthesis in dairy cows. J. Nutr. 137, 71-76. 
Loor, J.J., Herbein, J.H., Jenkins, T.C., 2002. Nutrient digestion, biohydrogenation and fatty acid profiles in blood plasma and milk fat from lactating Holstein cows fed canola oil or canolamide. Anim. Feed Sci. Technol. 97, 65-82.

Loor, J.J., Ueda, K., Ferlay, A., Chilliard, Y., Doreau, M., 2004. Biohydrogenation, duodenum flow and intestinal digestibility of trans fatty acids and conjugated linoleic acids in response to dietary forage:concentrate ratio and linseed oil in dietary cows. J. Dairy Sci. 87, $2472-2485$.

Loor, J.J., Ferlay, A., Ollier, A., Doreau, M., Chilliard, Y., 2005a. Relationship among trans and conjugated fatty acids and bovine milk fat yield due to dietary concentrate and linseed oil. J. Dairy Sci. 88, 726-740.

Loor, J.J., Ferlay, A., Ollier, A., Ueda, K., Doreau, M., Chilliard, Y., 2005b. High-concentrate diets and polyunsaturated oils alter trans and conjugated isomers in bovine rumen, blood, and milk. J. Dairy Sci. 88, 3986-3999.

Lourenço, M., Van Ranst, G., De Smet, S., Raes, K., Fievez, V., 2007. Effect of grazing pastures with different botanical composition by lambs on rumen fatty acid metabolism and fatty acid pattern of longissimus muscle and subcutaneous fat. Animal 1, 537-545.

Lourenço, M., Ramos-Morales, E., Wallace, R.J., 2010. The role of microbes in rumen lipolysis and biohydrogenation and their manipulation. Animal 4, $1008-1023$.

Mansbridge, R.J., Blake, J.S., 1997. Nutritional factors affecting the fatty acid composition of bovine milk. Brit. J. Nutr. 78 (S37), S47.

Markham, J.E., Edgar, J.Li, Cahoon, B., Jaworski, J.G., 2006. Separation and identification of major plant sphingolipid classes from leaves. J. Biol. Chem. 281, 22684-22694.

Martin, S.A., Jenkins, T.C., 2002. Factors affecting conjugated linoleic acid and trans-C18:1 fatty acid production by mixed ruminal bacteria. J. Anim. Sci. 80, 3347-3352.

Matos, A.R., Pham-Thi, A.T., 2009. Lipid deacylating enzymes in plants: old activities, new genes. Plant Physiol. Biochem. 47, 491-503.

McKain, N., Shingfield, K.J., Wallace, R.J., 2010. Metabolism of conjugated linoleic acids and 18:1 fatty acids by ruminal bacteria: products and mechanisms. Microbiology 156, 579-588.

Melo, N., Tavares, R.M., Morais, F., Barroso, J.G., Pais, M.S.S., 1995. Lipid composition of thylakoid membranes from leaves and regreened spathes of Zantedeschia aethiopica. Phytochemistry 40, 1367-1371.

Molle, G., Decandia, M., Sitzia, M., Cabiddu, A., Fois, N., Ligios, S., Giovannetti, V., Rutter, S.M., 2004. Foraging behaviour of sheep rotationally grazing annual ryegrass (Lolium rigidum Gaudin). In: Luscher, A., Jeangros, B., Kessler, W., Houguenin, O., Lobsiger, M., Millar, N., Suter, D. (Eds.), Land Use Systems in Grassland Dominated Regions. ETH Zentrum Zurich, Zurich, Switzerland, pp. 575-577.

Moon, C.D., Pacheco, D.M., Kelly, W.J., Leahy, S.C., Li, D., Kopecny, J., Attwood, G.T., 2008. Reclassification of Clostridium proteoclasticum as Butyrivibrio proteoclasticus comb. nov., a butyrate-producing ruminal bacterium. Int. J. Syst. Evol. Microbiol. 58, $2041-2045$.

Moorby, J.M., Dewhurst, R.J., Evans, R.T., Danelòn, J.L., 2006. Effects of dairy cow diet forage proportion on duodenal nutrient supply and urinary purine derivative excretion. J. Dairy Sci. 89, 3552-3562.

Moorby, J.M., Lee, M.R.F., Davies, D.R., Kim, E.J., Nute, G.R., Ellis, N.M., Scollan, N.D., 2009. Assessment of dietary ratios of red clover and grass silages on milk production and milk quality in dairy cows. J. Dairy Sci. 92, 1148-1160.

Moore, J.H., Noble, R.C., Steele, W., Czerkawski, J.W., 1969. Difference in the metabolism of esterified and unesterified linoleic acid by rumen microorganism. Brit. J. Nutr. 23, 869-878.

Mosley, E.E., Powell, G.L., Riley, M.B., Jenkins, T.C., 2002. Microbial biohydrogenation of oleic acid to trans isomers in vitro. J. Lipid Res. 43, 290-296.

Mosley, E.E., Shafii, B., Moate, P.J., McGuire, M.A., 2006. Cis-9, trans-11 conjugated linoleic acid is synthesized directly from vaccenic acid in lactating dairy cattle. J. Nutr. 136, 570-575.

Nam, I.S., Garnsworthy, P.C., 2007. Biohydrogenation of linoleic acid by rumen fungi compared with rumen bacteria. J. Appl. Microbiol. 103, 551-556.

Nelson, D.L., Cox, M.M., 2004. Lehninger Principles of Biochemistry, 4th ed. W.H. Freeman, New York, NY, USA, 1100 pp.

Nichols, B.W., 1963. Separation of the lipids of photosynthetic tissues: improvements in analysis by thin-layer chromatography. Biochim. Biophys. Acta 70, 417-422.

O’Brien, J.S., Benson, A.A., 1964. Isolation and fatty acid composition of the plant sulfolipids and galacolipids. J. Lip. Res. 5, $432-436$.

Offer, N.W., Marsden, M., Dixon, J., Speake, B.K., Thacker, F.E., 1999. Effect of dietary fat supplements on levels of $n-3$ polyunsaturated fatty acids, trans acids and conjugated linoleic acid in bovine milk. Anim. Sci. 69, 613-625.

Offer, N.W., Marsden, M., Phipps, R.H., 2001. Effect of oil supplementation of a diet containing a high concentration of starch on levels of trans fatty acids and conjugated linoleic acids in bovine milk. Anim. Sci. 73, 533-540.

Or-Rashid, M.M., Odongo, N.E., McBride, B.W., 2007. Fatty acid composition of ruminal bacteria and protozoa, with emphasis on conjugated linoleic acid, vaccenic acid, and odd-chain and branched-chain fatty acids. J. Anim. Sci. 85, 1228-1234.

Or-Rashid, M.M., AlZahal, O., McBride, B.W., 2011. Comparative studies on the metabolism of linoleic acid by rumen bacteria, protozoa, and their mixture in vitro. Appl. Microbiol. Biotechnol. 89, 387-395.

Orr, R.J., Penning, P.D., Harvey, A., Champion, R.A., 1997. Diurnal patterns of intake rate by sheep grazing monocultures of ryegrass or white clover. Appl. Anim. Behav. Sci. 52, 65-77.

Palmquist, D.L., Jenkins, T.C., 1980. Fat in lactation rations: review. J. Dairy Sci. 63, 1-14.

Palmquist, D.L., St-Pierre, N., McClure, E., 2004. Tissue fatty acid profiles can be used to quantify endogenous rumenic acid synthesis in lambs. J. Nutr. 134 , 2407-2414.

Perfield, J.W., Lock, A.L., Griinari, J.M., Sæbø, A., Delmonte, P., Dwyer, D.A., Bauman, D.E., 2007. Trans-9, cis-11 conjugated linoleic acid (CLA) reduces milk fat synthesis in lactating dairy cows. J. Dairy Sci. 90, 2211-2218.

Perrier, R., Doreau, B.M., Bauchart, D., Doreau, M., 1992. Assessment of an is situ technique to estimate the degradation of lipids in the rumen. J. Sci. Agric. 59, 449-455.

Peterson, D.G., Matitashvili, E.A., Bauman, D.E., 2003. Diet induced milk fat depression in dairy cows results in increased trans-10, cis-12 CLA in milk fat and coordinate suppression of mRNA abundance for mammary enzymes involved in milk fat synthesis. J. Nutr. 133, 3098-3102.

Piperova, L.S., Teter, B.B., Bruckental, I., Sampugna, J., Mills, S.E., Yurawecz, M.P., Fritsche, J., Ku, K., Erdman, R.A., 2000. Mammary lipogenic enzyme activity, trans fatty acids and conjugated linoleic acids are related in lactating dairy cows fed a milk fat-depressing diet. J. Nutr. $130,2568-2574$.

Piperova, L.S., Sampugna, J., Teter, B.B., Kalscheur, K.F., Yurawecz, M.P., Ku, Y., Morehouse, K.M., Erdman, R.A., 2002. Duodenal and milk trans octadecanoic acid and conjugated linoleic acid (CLA) isomers indicate that postabsorptive synthesis is the predominant source of cis-9-containing CLA in lactating dairy cows. J. Nutr. $132,1235-1241$.

Quartacci, M.F., Pinho, C., Sgherri, C.L.M., Navari-lzzo, F., 1995. Lipid composition and two wheat cultivars protein dynamics in thylakoids of differently sensitive to drought. Plant Physiol. 108, 191-197.

Reiser, R., 1951. Hydrogenation of polyunsaturated fatty acids by the ruminant. Fed. Proc. 10, 236.

Rigout, S., Hurtaud, C., Lemosquet, S., Bach, A., Rulquin, H., 2003. Lactation effects of propionic acid and duodenal glucose in cows. J. Dairy Sci. 86, 243-253.

Roughan, P.G., Batt, R.D., 1969. The glycerolipid composition of leaves. Phytochemistry 8, 363-369.

Roughan, P.G., Boardman, N.K., 1972. Lipid composition of pea and bean leaves during chloroplast development. Plant Physiol. 50, 31-34.

Sæbø, A., Sæbø, P., Griinari, J.M., Shingfield, K.J., 2005. Effect of abomasal infusion of geometric isomers of 10,12 conjugated linoleic acid on milk fat synthesis in dairy cows. Lipids 40, 823-832.

Schwertner, H.A., Biale, J.B., 1973. Lipid composition of plant mitochondria and of chloroplasts. J. Lip. Res. 14, $235-242$.

Selner, D.R., Schultz, R.H., 1980. Effects of feeding oleic acid or hydrogenated vegetable oils to lactating cows. J. Dairy Sci. 63, $1235-1241$.

Shen, X., Dannenberger, D., Nuernberg, K., Nuernberg, G., Zhao, R., 2011. Trans-18:1 and CLA isomers in rumen and duodenal digesta of bulls fed n-3 and n-6 PUFA-based diets. Lipids 46, 831-841.

Shingfield, K.J., Ahvenjarvi, S., Toivonen, V., Arola, A., Nurmela, K.V.V., Huhtanen, P., Griinari, J.M., 2003. Effect of dietary fish oil on biohydrogenation of fatty acids and milk fatty acid content in cows. Anim. Sci. 77, 165-179. 
Shingfield, K.J., Reynolds, C.K., Lupoli, B., Toivonen, V., Yurawecz, M.P., Delmonte, P., Griinari, J.M., Grandison, A.S., Beever, D.E., 2005. Effect of forage type and proportion of concentrate in the diet on milk fatty acid composition in cows given sunflower oil and fish oil. Anim. Sci. 80, $225-238$.

Shingfield, K.J., Griinari, J.M., 2007. Role of biohydrogenation intermediates in milk fat depression. Eur. J. Lipid Sci. Technol. 109, 799-816.

Shingfield, K.J., Ahvenjarvi, S., Toivonen, V., Vanhatalo, A., Huhtanen, P., Griinari, J.M., 2008. Effect of incremental levels of sunflower-seed oil in the diet on ruminal lipid metabolism in lactating cows. Brit. J. Nutr. 99, 971-983.

Shingfield, K.J., Sæbø, A., Sæbø, P.C., Toivonen, V., Griinari, J.M., 2009. Effect of abomasal infusions of a mixture of octadecanoic acids on milk fat synthesis in lactating cows. J. Dairy Sci. 92, 4317-4329.

Shingfield, K.J., Lee, M.R.F., Humphries, D.J., Scollan, N.D., Toivonen, V., Reynolds, C.K., Beever, D.E., 2010. Effect of incremental amounts of fish oil in the diet on ruminal lipid metabolism in growing steers. Brit. J. Nutr. 104, 56-66.

Shorland, F.B., Weenink, R.O., Goldfine, H., 1955. Effect of the rumen on dietary fat. Nature 175, 1129-1130.

Shorland, F.B., 1961. Acetone-soluble lipids of grasses and other forage plants. II general observation on the properties of the lipids with special references to the yield of fatty acids. J. Sci. Food Agric. 12, 39-43.

Singh, S., Hawke, J.C., 1979. The in vitro lipolysis and biohydrogenation of monogalactosyldiglycride by whole rumen content and its fractions. J. Sci. Food Agric. 30, 603-612.

Song, X., Qi, X., Hao, B., Qu, Y., 2008. Studies of substrate specificities of lipases from different sources. Eur. J. Lipid Sci. Technol. 110, 1095-1101.

Sperling, P., Heinz, E., 2003. Plant sphingolipids: structural diversity, biosynthesis, first genes and functions. Biochim. Biophys. Acta 1632, 1-15.

Steinshamn, H., 2010. Effect of forage legumes on feed intake, milk production and milk quality-a review. Anim. Sci. Pap. Rep. 28, $195-206$.

Tamminga, S., Doreau, M., 1991. Lipids and rumen digestion. In: Jouany, J.P. (Ed.), Rumen Microbial Metabolism and Ruminant Digestion. INRA éditions, Paris, France, pp. 151-163.

Ulberth, F., Henninger, M., 1994. Quantitation of trans fatty acids in milk fat using spectroscopy and chromatographic methods. J. Dairy Res. 61, 517-527.

Van de Vossenberg, J.L., Joblin, K.N., 2003. Biohydrogenation of C18 unsaturated fatty acids to stearic acid by a strain of Butyrivibrio hungatei from the bovine rumen. Lett. Appl. Microbiol. 37, 424-428.

Van Dorland, H.A., Kreuzer, M., Leuenberger, H., Wettstein, H.R., 2008. Comparative potential of white and red clover to modify the milk fatty acid profile of cows fed ryegrass-based diets from zero-grazing and silage system. J. Sci. Food Agric. 88, 77-85.

Van Ranst, G., Fievez, V., De Riek, J., Van Bockstaele, E., 2009. Influence of ensiling forages at different dry matters and silage additives on lipid metabolism and fatty acid composition. Anim. Feed Sci. Technol. 150, 62-74.

Van Ranst, G., Fievez, V., Vandewalle, M., Van Waes, C., De Riek, J., Van Bockstaele, E., 2010. Influence of damaging and wilting red clover on lipid metabolism during ensiling and in vitro rumen incubation. Animal 9, 1528-1540.

Van Ranst, G., Lee, M.R.F., Fievez, V., 2011. Red clover polyphenol oxidase and lipid metabolism. Animal 5, $512-521$.

Vanhatalo, A., Kuoppala, K., Toivonen, V., Shingfield, K.J., 2007. Effects of forage species and stage of maturity on bovine milk fatty acid composition. Eur. J. Lipid Sci. Technol. 109, 856-867.

Varadyova, Z., Kisidayova, S., Siroka, P., Jalc, D., Varadyova, Z., Kisidayova, S., Siroka, P., Jalc, D., 2008. Comparison of fatty acid composition of bacterial and protozoal fractions in rumen fluid of sheep fed diet supplemented with sunflower, rapeseed and linseed oils. Anim. Feed Sci. Technol. $144,44-54$.

Vasta, V., Makkar, H.P.S., Mele, M., Priolo, A., 2009a. Ruminal biohydrogenation as affected by tannins in vitro. Brit. J. Nutr. $102,82-92$.

Vasta, V., Mele, M., Serra, A., Scerra, M., Luciano, G., Lanza, M., Priolo, A., 2009b. Metabolic fate of fatty acids involved in ruminal biohydrogenation in sheep fed concentrate or herbage with or without tannins. J. Anim. Sci. 87, 2674-2684.

Vlaeminck, B., Dewhurst, R.J., Demeyer, D., Fievez, V., 2004a. Odd and branched chain fatty acids to estimate proportions of cellulolytic and amylolytic particle associated bacteria. J. Anim. Feed Sci. 13, 235-238.

Vlaeminck, B., Fievez, V., van Laar, H., Demeyer, D., 2004b. Rumen odd and branched chain fatty acids in relation to in vitro rumen volatile fatty acid productions and dietary characteristics of incubated substrates. J. Anim. Physiol. Anim. Nutr. 88, 401-411.

Vlaeminck, B., Dufour, C., Van Vuuren, A.M., Cabrita, A.R.J., Dewhurst, R.J., Demeyer, D., Fievez, V., 2005. Use of odd and branched-chain fatty acids in rumen contents and milk as a potential microbial marker. J. Dairy Sci. 88, 1031-1042.

Vlaeminck, B., Fievez, V., Cabrita, A.R.J., Fonseca, A.J.M., Dewhurst, R.J., 2006a. Factors affecting odd- and branched-chain fatty acids in milk: a review. Anim. Feed Sci. Technol. 131, 389-417.

Vlaeminck, B., Fievez, V., Demeyer, D., Dewhurst, R.J., 2006b. Effect of forage:concentrate ratio on fatty acid composition of rumen bacteria isolated from ruminal and duodenal digesta. J. Dairy. Sci. 89, 2668-2678.

Vlaeminck, B., Fievez, V., Tamminga, S., Dewhurst, R.J., Van Vuuren, A., De Brabander, D., Demeyer, D., 2006c. Milk odd- and branched-chain fatty acids in relation to the rumen fermentation pattern. J. Dairy Sci. 89, 3954-3964.

Vlaeminck, B., Mengistu, G., Fievez, V., De Jonge, L., Dijkstra, J., 2008. Effect of in vitro docosahexaenoic acid supplementation to marine algae-adapted and unadapted rumen inoculum on the biohydrogenation of unsaturated fatty acids in freeze-dried grass. J. Dairy. Sci. 91, $1122-1132$.

Wachira, A.M., Sinclair, L.A., Wilkinson, R.G., Hallett, K., Enser, M., Wood, J.D., 2000. Rumen biohydrogenation of $n-3$ polyunsaturated fatty acids and their effects on microbial efficiency and nutrient digestibility in sheep. J. Agric. Sci. 135, 419-428.

Wallace, R.J., Chaudhary, L.C., McKain, N., McEwan, N.R., Richardson, A.J., Vercoe, P.E., Walker, N.D., Paillard, D., 2006. Clostridium proteoclasticum: a ruminal bacterium that forms stearic acid from linoleic acid. FEMS Microbiol. Lett. 265, 195-201.

Wallace, R.J., McKain, N., Shingfield, K.J., Devillard, E., 2007. Isomers of conjugated linoleic acids are synthesized via different mechanisms in ruminal digesta and bacteria. J. Lipid Res. 48, 2247-2254.

Ward, P.F.V., Scott, T.W., Dawson, R.M.C., 1964. The hydrogenation of unsaturated fatty acids in the ovine digestive tract. J. Biochem. 92, 60-68.

Warnecke, D., Heinz, E., 2003. Recently discovered functions of glucosylceramides in plants and fungi. Cell. Mol. Life Sci. 60, 919-941.

Wasowska, I., Maia, M.R.G., Niedzwiedzka, K.M., Czauderna, M., Ramalho Ribeiro, J.M.C., Devillard, E., Shingfield, K.J., Wallace, R.J., 2006. Influence of fish oil on ruminal biohydrogenation of C18 unsaturated fatty acids. Brit. J. Nutr. 95, 1199-1211.

Weenink, R.O., 1961. Acetone-soluble lipids of grasses and other forage plants. I. Galactolipids of red clover (Trifolium pretense) leaves. J Sci. Food Agric. 12, 34-38.

Weenink, R.O., 1962. Minor constituent of the acetone soluble lipids of red clover (Trifolium pretense) leaves. J. Biochem. 82, $523-527$.

Whitlock, L.A., Schingoethe, D.J., Hippen, A.R., Kalscheur, K.F., Baer, R.J., Ramaswamy, N., Kasperson, K.M., 2002. Fish oil and extruded soybeans fed in combination increase conjugated linoleic acids in milk of dairy cows more than when fed separately. J. Dairy Sci. 85, $234-243$.

Wilde, P.F., Dawson, R.M.C., 1966. The biohydrogenation of $\alpha$-linolenic and oleic acid by rumen micro-organisms. J. Biochem. 98 , $469-475$.

Wood, T.A., Ramos-Morales, E., McKain, N., Shen, H., Atasoglu, C., Wallace, R.J., 2010. Chrysanthemum coronarium as a modulator of fatty acid biohydrogenation in the rumen. Anim. Feed Sci. Technol. 161, 28-37.

Yàňez-Ruiz, D.R., Scollan, N.D., Merry, R.J., Newbold, C.J., 2006. Contribution of rumen protozoa to duodenal flow of nitrogen, conjugated linoleic acid and vaccenic acid in steers fed silages differing in their soluble carbohydrate content. Brit. J. Nutr. 96, 861-869.

Yàňez-Ruiz, D.R., Williams, S., Newbold, C.J., 2007. Effect of the absence of protozoa on rumen biohydrogenation and the fatty acid composition of lamb muscle. Brit. J. Nutr. 97, 938-948.

Yokoyama, M.T., Davis, C.L., 1971. Hydrogenation of unsaturated fatty acids by Treponema Borrelia strain B25, a rumen spirochete. J. Bacteriol. 107, 519-527. 